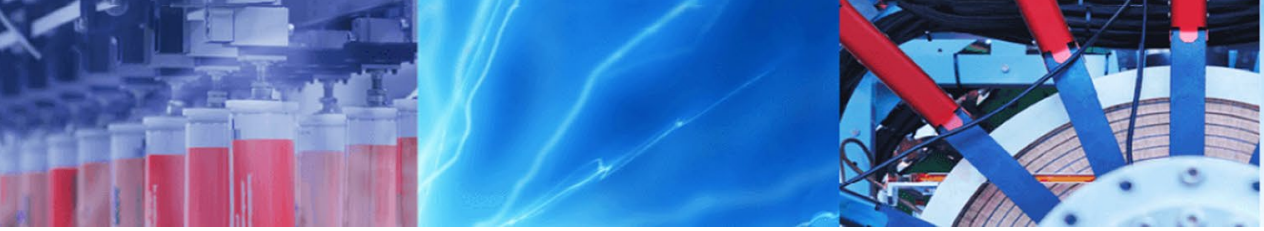

Research Article

\title{
Low Reynolds airfoil family for small horizontal axis wind turbines based on RG15 airfoil
}

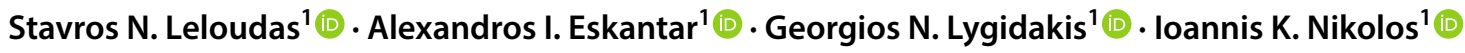

Received: 31 October 2019 / Accepted: 3 February 2020 / Published online: 10 February 2020

(c) Springer Nature Switzerland AG 2020

\begin{abstract}
The present study introduces a low Reynolds number $(R e)$ airfoil family for the entire blade span of small wind turbines, aiming to reduce the effects related to laminar separation, improve startup response and meet acceptable levels of structural integrity. Six airfoils of varying relative thickness were designed by increasing the thickness distribution of RG15 airfoil up to $50 \%$ and adopting a rounded trailing edge with a diameter equal to $1 \%$ of the chord length. The aerodynamic performance of RG15 family was initially evaluated by means of XFOIL code at several low Reynolds numbers ranging from 60,000 to 300,000 and angles of attack between $-6^{\circ}$ and $14^{\circ}$. XFOIL analysis revealed that increasing relative thickness leads to the reduction of maximum lift-to-drag ratio $\left(C_{L} / C_{D}\right)$. However, this percentage reduction decreases with increasing $\operatorname{Re}$. The maximum reduction in maximum $C_{L} / C_{D}$ was found at 60,000 Re for the thickest airfoil of RG15 family. Conversely, a growth of maximum lift coefficient $\left(C_{L}\right)$ was observed by increasing relative thickness. Besides, a Reynolds-Averaged Navier-Stokes (RANS) analysis was also conducted at 300,000 Re to get additional information on the flow characteristics. Comparisons between the XFOIL and RANS data were performed. The results of RANS simulations were generally in accordance with those of XFOIL. However, notable over-estimations of drag coefficient $\left(C_{D}\right)$ were detected. The behavior of the recirculation area behind the rounded trailing edge and that of the separation bubble near the leading edge for different values of relative thickness and angle of attack was examined. Thickening of the airfoils was found to have a beneficial impact on the appearance of separation bubbles, while no significant effect of the rounded trailing edge on $C_{L}$ and $C_{D}$ was observed.
\end{abstract}

Keywords Low Reynolds airfoils · Aerodynamics · Small wind turbines $\cdot$ XFOIL $\cdot$ RANS · SST

\section{Introduction}

On account of global efforts to reduce greenhouse gases emissions and combat climate change, small-scale wind energy conversion systems have recently attracted renewed attention from the international engineering community, since they represent a promising solution for sustainable energy production in site-specific cases. In contrast to their larger counterparts, small wind turbines provide a considerably higher level of flexibility, both in terms of required space and wind speed conditions [1].
Therefore, they can be integrated within a much broader spectrum of residential, rural and remote areas for either on-grid or off-grid power generation-usually directly where the power is required, rather than where the wind is most favorable-enabling significant opportunities for more geographic dispersion of wind technology applications [2], growth in distributed energy deployments, and further expansion of renewable energy utilization on a global scale.

Small horizontal-axis wind turbines (HAWTs), which according to the standards issued by the International

Stavros N. Leloudas, sleloudas@isc.tuc.gr | 'School of Production Engineering and Management, Technical University of Crete, 73100 Chania, Greece. 
Electrotechnical Commission [3] are characterized by a rotor swept area of less than $200 \mathrm{~m}^{2}$, rely on the same aerodynamic principles governing the operation of larger HAWT systems. However, the chord Reynolds numbers $(R e)$ prevailing along the entire blade span of the former applications are considerably lower-generally below 500,000 - as a consequence of the smaller blade radius [4]. One of the major aspects of high Reynolds number flows over airfoils is that the transition from laminar to turbulent flow inside the velocity boundary layer is realized earlier than laminar separation. Eventually, this early transition prevents the appearance of undesirable aerodynamic effects related to the latter phenomenon [5], since a turbulent boundary layer is capable of withstanding an adverse pressure gradient (that is an increase of static pressure in the direction of the flow) better than an equivalent laminar one. On the contrary, at low Reynolds number regimes-typically defined by a chord Reynolds number lower than approximately 500,000 - the boundary layer is predominantly laminar and therefore, relatively fragile [4]. In that case, the existence of a large adverse pressure gradient may force the flow to detach prematurely from the surface of the airfoil, that is, prior to the development of a fully turbulent flow. Even though the resultant free shear layer (detached boundary layer) remains laminar shortly after the separation point, it eventually transits to the turbulent state due to the intensification of the velocity disturbances in the flow [6] (separation-induced transition). From that point on, two distinct flow regimes may result; the so-called subcritical and supercritical flow regimes [7], which are represented in Figs. 1 and 2.

In a supercritical flow, the detached (now turbulent) shear layer does reattach to the surface of the airfoil, causing the formation of a laminar separation bubble, the size and chordwise location of which are functions of the airfoil profile, Reynolds number, turbulence intensity $\left(T_{u}\right)$ and angle of attack (a) [8]. Typically, a separation bubble moves towards the leading edge as the angle of attack increases [5]. In terms of size, laminar separation bubbles can be roughly classified as either short or long ones, depending on their chordwise extent $\left(L_{s b}\right)$ and consequent effects on the pressure and velocity distributions about the airfoil [9]. A short separation bubble encompasses a chordwise extent ranging up to approximately one percent; therefore, it does not influence the pressure distribution around the airfoil to a large degree. However, a long separation bubble (usually produced by the burst of a short one, because of either the reduction in Reynolds number or the increase in angle of attack) may cover a significantly larger percent of the airfoil chord, affecting severely the pressure distribution and the aerodynamic forces developed on the airfoil [10].

Although the existence of a laminar separation bubble near the leading edge at high angles of attack may increase the apparent camber of the airfoil and improve the lift $(L)$ generation capacity [11], it ultimately thickens (locally) the velocity boundary layer on the suction side, increasing considerably the drag coefficient $\left(C_{D}\right)$ as well. In addition to that, the presence of laminar separation bubble is also associated with a turbulent flow separation near the trailing edge of the airfoil, as exemplified in Fig. 2a, b; this characteristic phenomenon of the supercritical flow regime is known as trailing edge stall [7]. Besides, the potential premature burst of a laminar separation bubble could cause an even larger growth of the drag coefficient, which is accompanied by a sudden and severe loss of the generated lift [11]. Now, in contrast to the supercritical regime, if the turbulent transition takes place far away from the surface of the airfoil, there is a possibility that the turbulent shear layer may not be able to reattach to the airfoil surface, creating an open separation area (subcritical flow) instead of a separation bubble. In that case, a thicker and extremely unstable wake region is produced, as shown in Fig. 2c, resulting in much higher drag $(D)$ levels and further reduction in the aerodynamic performance of the airfoil, compared to the supercritical flow regime. However, such an unattached free shear layer (open separation area) may also

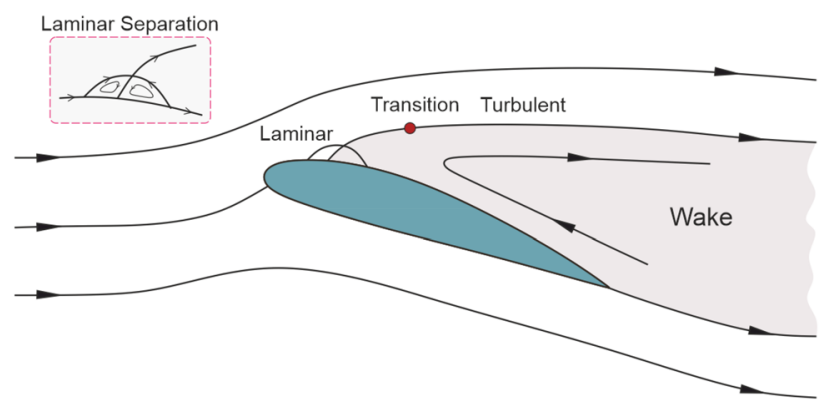

(a)

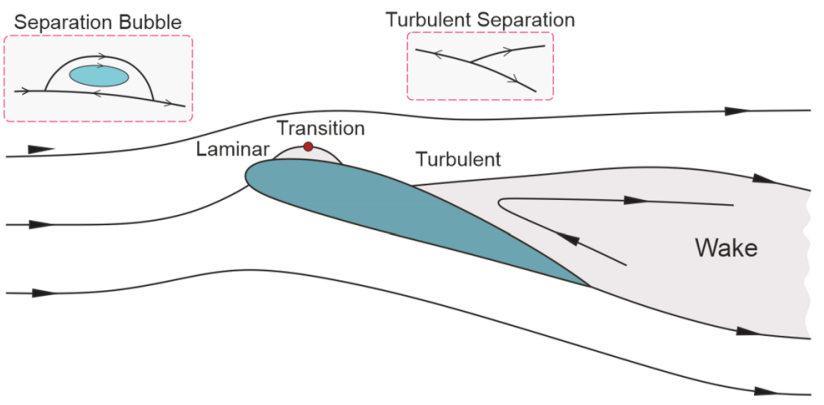

(b)

Fig. 1 Schematic representation of laminar flow separation. a Subcritical flow regime. b Supercritical flow regime 


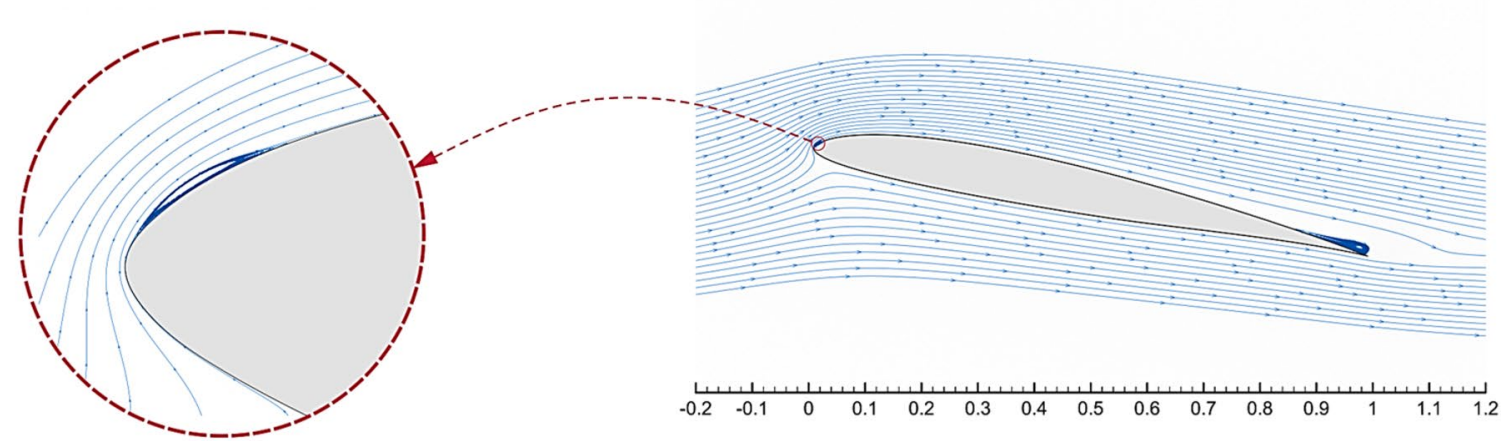

(a)

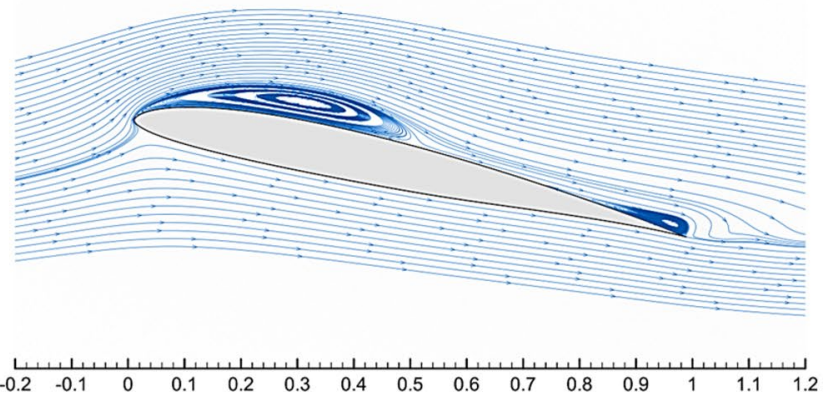

(b)

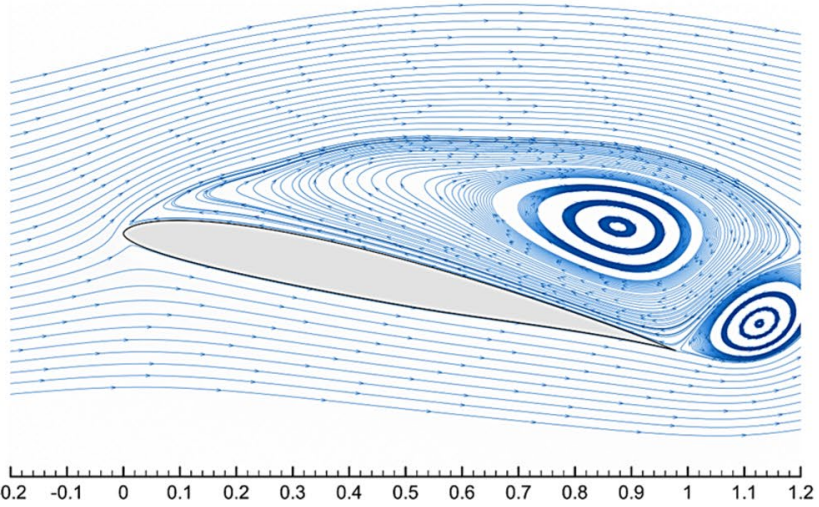

(c)

Fig. 2 Velocity streamlines for different flow regimes. a Short separation bubble (supercritical regime). b Long separation bubble (supercritical regime). c Unattached shear layer (subcritical regime)

be produced by the bursting of a laminar separation bubble.

Therefore, to optimize the aerodynamic performance of small wind turbine blades, operating at low Reynolds numbers, the effects related to laminar separation have to be minimized. One of the available methods to reduce or even eliminate bubble drag (that is drag induced by a laminar separation bubble)-as well as to delay the possible chances of separation at higher angles of attack-is related to the promotion of early transition on the upper surface (suction side) of the airfoil, through the installation of a mechanical turbulator or trip [1]. However, the particular technique, which is the only one applicable to existing airfoils [5], requires adequate experience in selecting the proper location and thickness of the trip, so as to maximize the reduction in bubble drag while minimizing the drag produced by the trip [12]. On the other hand, according to Giguere and Selig [5], the suppression of laminar separation effects could also be achieved by means of specially designed airfoils with a very gradual upper-surface pressure recovery (bubble ramp), which can decrease significantly the additional drag induced by separation bubbles. Currently, the majority of low Reynolds number airfoils are designed based on the latter technique, providing reduced amounts of drag and higher maximum lift-to-drag ratios (also termed as glide ratios), as compared with those of traditional airfoils that have been mainly designed for high Reynolds numbers and, therefore, they usually suffer from severe laminar separation effects when operating at low Reynolds number regimes.

The first airfoils for small wind turbines were introduced by the National Renewable Energy Laboratory (NREL); the S822 and S823 airfoils [13] were particularly designed for small stall-regulated wind turbines with a rotor diameter between 3 and 10 meters, based on the following criteria: restrained maximum lift, insensitivity to roughness and low profile drag. Nevertheless, the first systematic attempt to establish a wide database of low Reynolds number airfoils for small wind turbine blades was made by Giguere and Selig [5]. In that study, the aerodynamic performance of 15 already existing low Reynolds number airfoils (most of them had been originally designed for small unmanned aerial vehicles) was thoroughly evaluated, based on the results of a large-scale testing program undertaken in the University of Illinois at Urbana-Champaign (UIUC) low-turbulence subsonic wind tunnel [14]. Besides, Giguere and 
Selig [5] provided useful guidelines to facilitate the airfoil selection process for each one of the different operational modes of small wind turbines (variable-speed, variablepitch, stall regulated). Later on, Giguere and Selig [15] introduced the SG604x airfoil family, which was designed by taking into consideration the special requirements of small variable-speed wind turbines with a rated capacity up to $5 \mathrm{~kW}$. The SG604x airfoil family was formed by three primary airfoils (SG6041, SG6042 and SG6043) with a maximum relative thickness of $10 \%$ and by one root airfoil (SG6040) with a maximum relative thickness of $16 \%$, to accommodate possible large root bending moment and large blade stiffness requirements. According to both experimental and numerical data reported in [15], the SG604x family could achieve high lift-to-drag ratios (L/D) over a broad range of lift conditions. Moreover, Selig and McGranahan [16] conducted detailed wind tunnel experiments in order to examine the performance characteristics of six low Reynolds number airfoils (E387, FX 63-137, S822, S834, SD2030 and SH3055) for small wind turbines, at various Reynolds numbers up to 500,000.

Significant research on small wind turbine airfoils was also made by Ram et al. [17], who employed a Genetic Algorithm to design a low Reynolds number airfoil with high roughness insensitivity and maximum relative thickness of $10 \%$. The resultant USPT2 airfoil was evaluated both numerically and experimentally. According to the corresponding results reported in [17], USPT2 seemed to overperform the SG6043 airfoil in terms of lift-to-drag ratio for angles of attack greater than $10^{\circ}$, while a smother stall region, as compared to that of similar airfoils, was also observed. On the other hand, Henriques et al. [18] applied a pressure-load prescription method to design a new airfoil (T.Urban 10/193) with high lift performance $\left(C_{L}\right.$ value around 2) for urban wind turbines. In comparison with conventional blade section designs, the T.Urban 10/193 airfoil demonstrated increased maximum lift, reduced leading edge suction peak and controlled soft-stall behavior, due to a reduction of the adverse pressure gradient on the suction side [18]. More recent research on small wind turbine airfoil design can also be found in the studies of Singh et al. [1], Shah et al. [4], Islam et al. [19], Marnett et al. [20] and Shen et al. [21]. In particular, the study of Singh et al. [1] was focused on the design of a new low Reynolds number airfoil, aiming to improve the startup behavior and low wind speed performance of small wind turbines. Compared with other low Reynolds number airfoils suited for small wind turbines, the proposed AF300 airfoil showed good aerodynamic performance, attaining the highest combinations of optimum $C_{L}$ and lift-todrag ratios. Moreover, Singh et al. [1] highlighted that the flatback trailing edge of the AF300 airfoil had improved the aerodynamic properties of AF300 by delaying flow separation and increasing $C_{L}$. Finally, they noted that the structural strength added by the thick trailing edge would require lighter blade materials and decrease the rotor inertia. Therefore, the startup could be significantly improved and the rotor could operate at lower cut-in wind speeds [1].

Apart from the suppression of laminar separation effects, the achievement of a good starting behavior (startup response) and low cut-in speeds can also enhance significantly the overall performance of small wind turbines intended for low/moderate wind speeds and fluctuating regimes. According to [22], a good startup can be succeeded by selecting root airfoils with high maximum lift coefficients $\left(C_{L}\right)$ and high lift-to-drag ratios, since most of the starting torque is caused by the blade root, whereas the tip region generates most of the power producing torque [23]. The RG15 is one of the attractive low Reynolds number airfoils-both in terms of aerodynamic performance and low Reynolds behavior-that were examined during the testing program at UIUC low-turbulence subsonic wind tunnel [14]. However, the particular airfoil is rather unsuitable for the root region of the blade, because of its limited structural integrity (limited rigidity and stiffness), stemming from the small value of the thickness-to-chord ratio $(t / c)$ and cross-sectional area $(A)$. Against this background, this work presents the development and application of a methodology for the design of a low Reynolds number airfoil family, suitable for the entire blade span of small wind turbines, through the proper thickening of the RG15 airfoil. Moreover, since the original RG15 airfoil geometry has a knife-sharp trailing edge, which does not meet the current blade manufacturing and transportation limitations, the original and the thickened airfoils are further modified, to result in a rounded trailing edge, without truncating the provided airfoil geometries. Ultimately, the aim of this study is to extend the use of this promising low Reynolds number airfoil and provide an adequate airfoil family for the entire blade span (including the root region as well) of small wind turbine blades, capable of significantly improving the overall power performance.

The remainder of this paper has been organized as follows: In Sect. 2, the original RG15 airfoil is presented, along with the experimental results of the testing program conducted at the UIUC low-turbulence subsonic wind tunnel [14]. Sections 3 and 4 provide a detailed description of the developed methodology for the construction of the RG15 airfoil family; the RG15 airfoil family is entirely presented in Sect. 5. In Sects. 6 and 7, the numerical procedure, involving the use the well-known XFOIL software and an in-house developed 2D Reynolds-Averaged Navier-Stokes (RANS) solver, for the aerodynamic evaluation of the RG15 airfoil family is thoroughly described. Finally, Sect. 8 
provides the numerical results obtained from both XFOIL and RANS solvers, while Sect. 9 contains the major conclusions of this work.

\section{The RG15 airfoil}

The RG15 low Reynolds number airfoil was designed by Rolf Girsberger in an attempt to provide a superior alternative-in terms of maximum $C_{L}$ - to the Eppler E180 airfoil and meet the special requirements of the FAI-F3B class that is the World Championship for Model Gliders. Even though RG15 was initially intended exclusively for radio controlled sailplanes and model gliders, including slope soaring and electric powered gliders, it currently represents an attractive low Reynolds number airfoil for the design of small wind turbine blades as well. Figure 3a presents the theoretical profile of the RG15 airfoil, which has a maximum relative thickness of $8.92 \%$ located at $30.2 \%$ of the chord from the leading edge and a maximum relative camber of $1.8 \%$ located at $39.7 \%$ of the chord from the leading edge.

The theoretical profile of the RG15 airfoil was generated by means of the Eppler airfoil code, according to the following criteria:

(a) Section drag for low lift ( $C_{L}$ between 0 and 0.4) comparable to $\mathrm{E} 180$ airfoil.

(b) Lower edge of laminar drag bucket at slightly negative lift.

(c) Higher maximum lift than E180 airfoil.

(d) Critical Reynolds number well below 100,000.

(e) Higher absolute value of pitching moment than E180 airfoil.

(f) Lower absolute value of pitching moment than E193 airfoil.

(g) Relative airfoil thickness between 8.5 and 9.5\%.

In addition, Fig. $3 \mathrm{~b}$ illustrates the actual airfoil profile used during the experimental study at the UIUC low-turbulence subsonic wind tunnel [14].

Since low Reynolds number airfoil performance is highly dependent on the laminar boundary layer behavior,

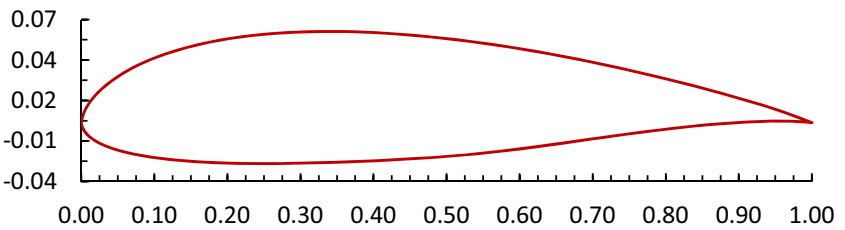

(a) low turbulence levels within the wind tunnel were necessary to ensure that laminar flow does not prematurely transition to the turbulent state over the airfoil surface. To this end, the wind-tunnel settling chamber had been equipped with a 4-in thick honeycomb and four anti-turbulence screens; the turbulence intensity was measured to be less than $0.1 \%$, which was considered sufficient for low Reynolds number airfoil measurements [14]. In Fig. 4, the aerodynamic characteristics of the RG15 airfoil for various Reynolds numbers from $R e=60,000$ to $R e=300,000$ are illustrated, as obtained from the testing program at the UIUC low-turbulence subsonic wind tunnel [14]. As expected, the increase of $R e$ is associated with a reduction in drag coefficient and therefore, an increase of the lift-todrag ratio, since no significant variation of the lift curve with Re was observed for the examined angles of attack.

\section{Thickening of the RG15 airfoil}

During the selection of the airfoil sections for the optimum wind turbine blade design, the specific requirements of the different blade regions should be considered as well. In particular, structural requirements have higher priority than the aerodynamic ones for airfoil sections that form the root region of the blade, due to the high stresses they go through. However, increased aerodynamic efficiency is essential for airfoil sections located in the mid span and tip regions, because of their great impact on the rotor power output. Consequently, even though RG15 airfoil seems appropriate for the mid span and tip regions, because of its promising aerodynamic characteristics, it appears unsuitable for the root region, due to its limited structural integrity (limited rigidity and stiffness), resulting from the small value of the thickness-to-chord ratio and cross-sectional area. To this end, five new thickened airfoils have been designed, based on the original RG15 geometry, in order to create an airfoil database suitable for the root region formation of small wind turbine blades.

The five thickened airfoils have been constructed in such a way that they have the same mean camber line (MCL) compared to the original RG15 airfoil (in order to retain its desirable aerodynamic characteristics), but an

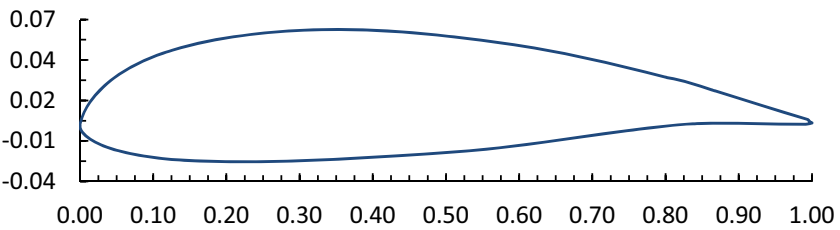

(b)

Fig. 3 The RG15 airfoil. a Theoretical profile. b Actual profile [14] 


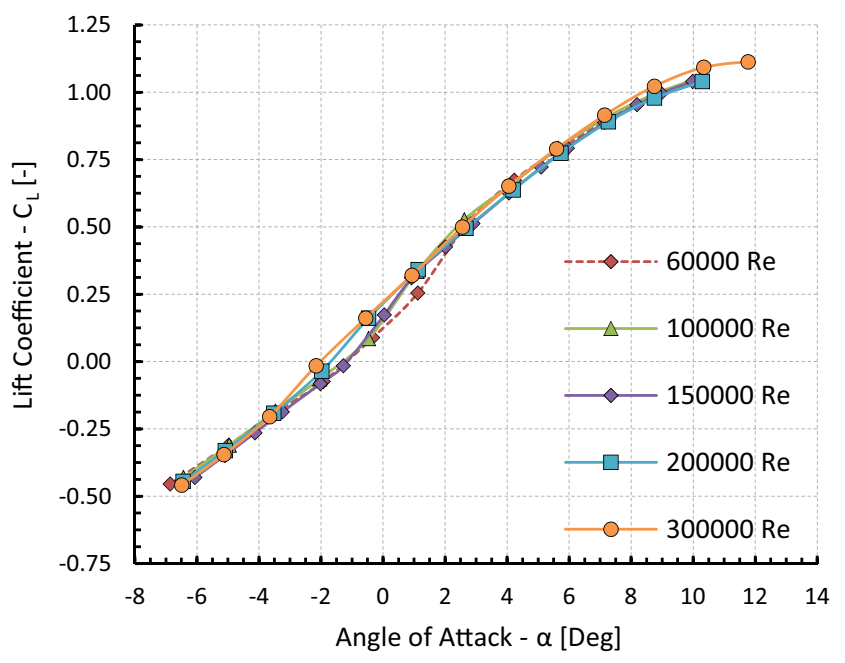

(a)

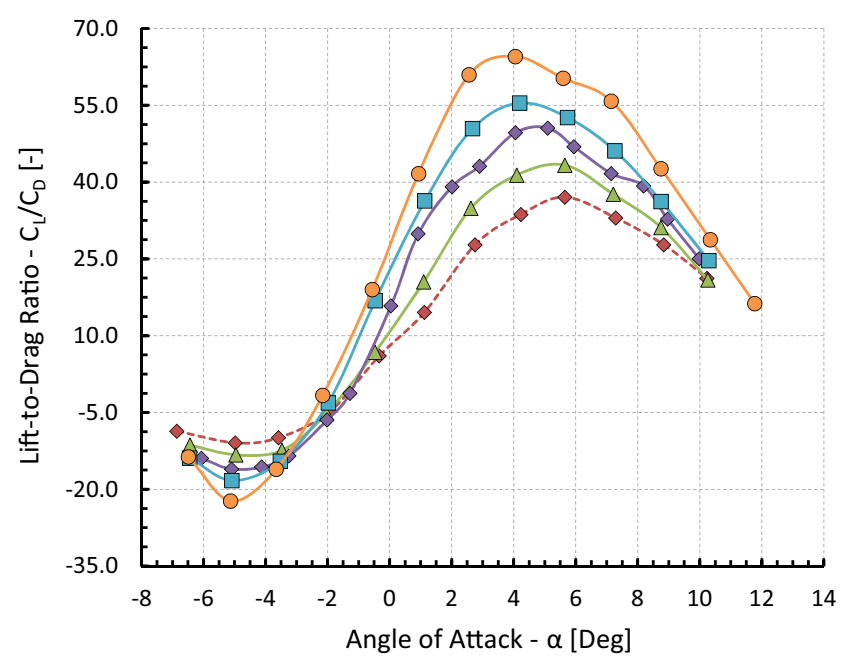

(c)

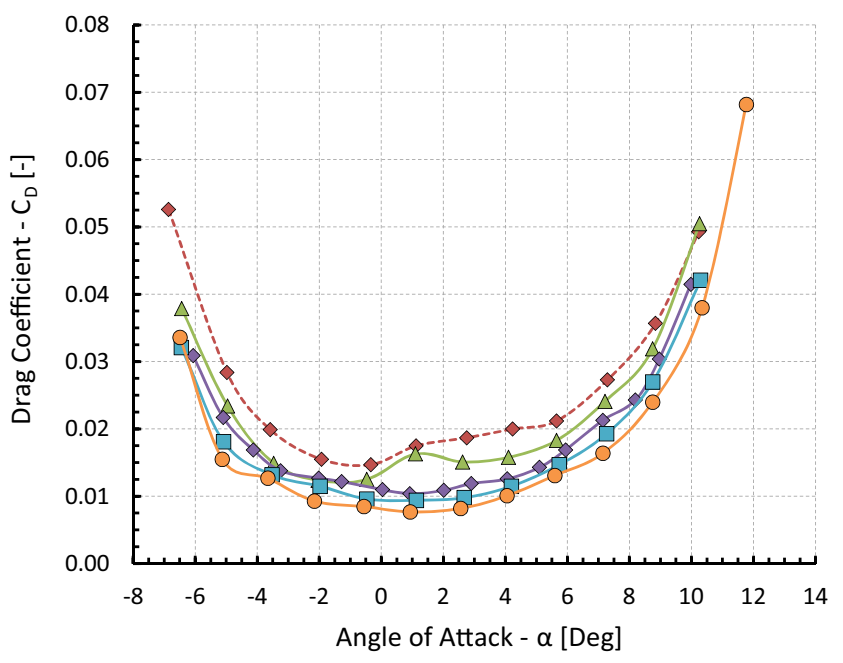

(b)

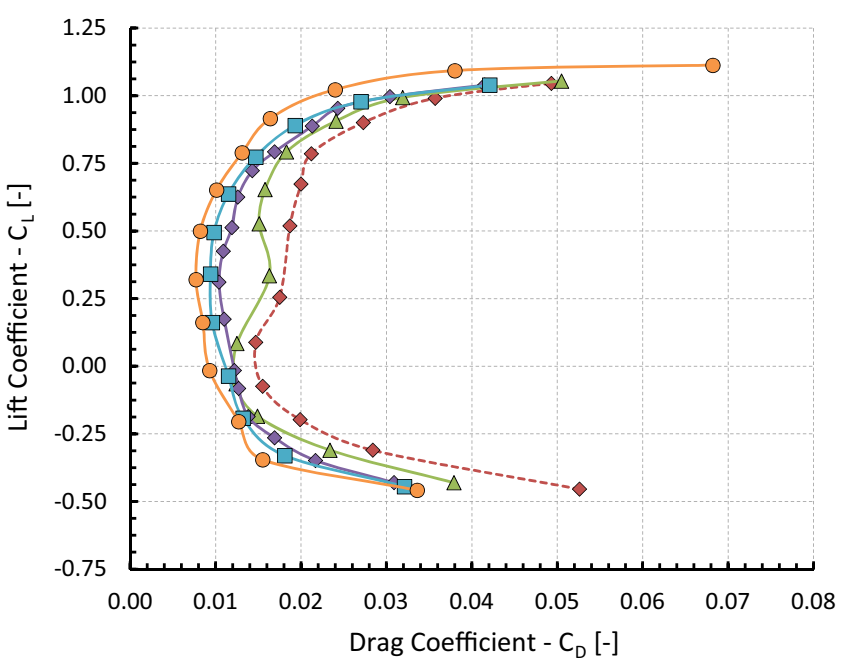

(d)

Fig. 4 Aerodynamic characteristics of the RG15 airfoil for several low Reynolds numbers, as measured at the UIUC wind tunnel [14]. a $C_{L}-\alpha$. b $C_{D}-\alpha \cdot \mathbf{c} C_{L} / C_{D}-\alpha \cdot \mathbf{d} C_{L}-C_{D}$

increased thickness-to-chord ratio distribution by $50 \%$, $40 \%, 30 \%, 20 \%$ and $10 \%$ respectively, compared to the base airfoil design. The construction of the five thickened airfoils, which from now on will be denoted as RG15-(50), RG15-(40), RG15-(30), RG15-(20) and RG15-(10), was implemented by the utilization of Rhinoceros 3D ComputerAided Design (CAD) application software, developed by
Robert McNeel \& Associates, as well as Grasshopper visual programming language, which runs within Rhinoceros.

Initially, the mean camber line of the original RG15 airfoil was calculated, by interpolating a smooth curve (blue line) through the centers (blue squares) of the inscribed circles (red circles) to the RG15 airfoil, as shown in Fig. 5 (standard procedure for calculating the MCL).

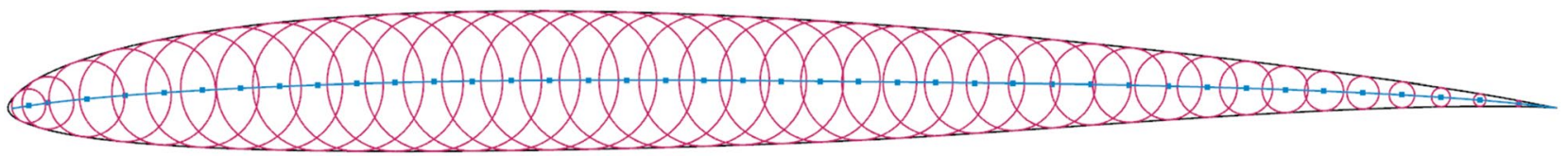

Fig. 5 Calculation of the RG15 mean camber line (blue line) 
Then, the thickness distribution of the RG15 airfoil was calculated, according to the following procedure (which is schematically represented in Fig. 6): for a point $k$ along the chord line $(c)$, the thickness value corresponding to $k$ is equal to the length of the line segment (thickness linemagenta) perpendicular to the MCL (blue) that passes through the projection of $k$ on the MCL.

In Fig. 7, only a few indicative thickness lines (magenta) of the RG15 airfoil are depicted for clarity purposes. Finally, as illustrated in Fig. 8, for the construction of the points of the new thickened airfoils, each thickness line of the original RG15 was extended equally from both sides by the appropriate percentage, depending on the desirable rate of thickness increase. The start and end points of the extended thickness lines (magenta squares-Fig. 8) are the points of the new thickened airfoil.

\section{Trailing edge modification}

The Kutta-Zhukovsky theorem dictates that a lift producing airfoil should have a knife-sharp trailing edge and therefore, it considers the practical necessity of manufacturing blades and wings with rounded trailing edges

Fig. 6 Calculation of the thickness line corresponding to a random point $k$ along the chord line
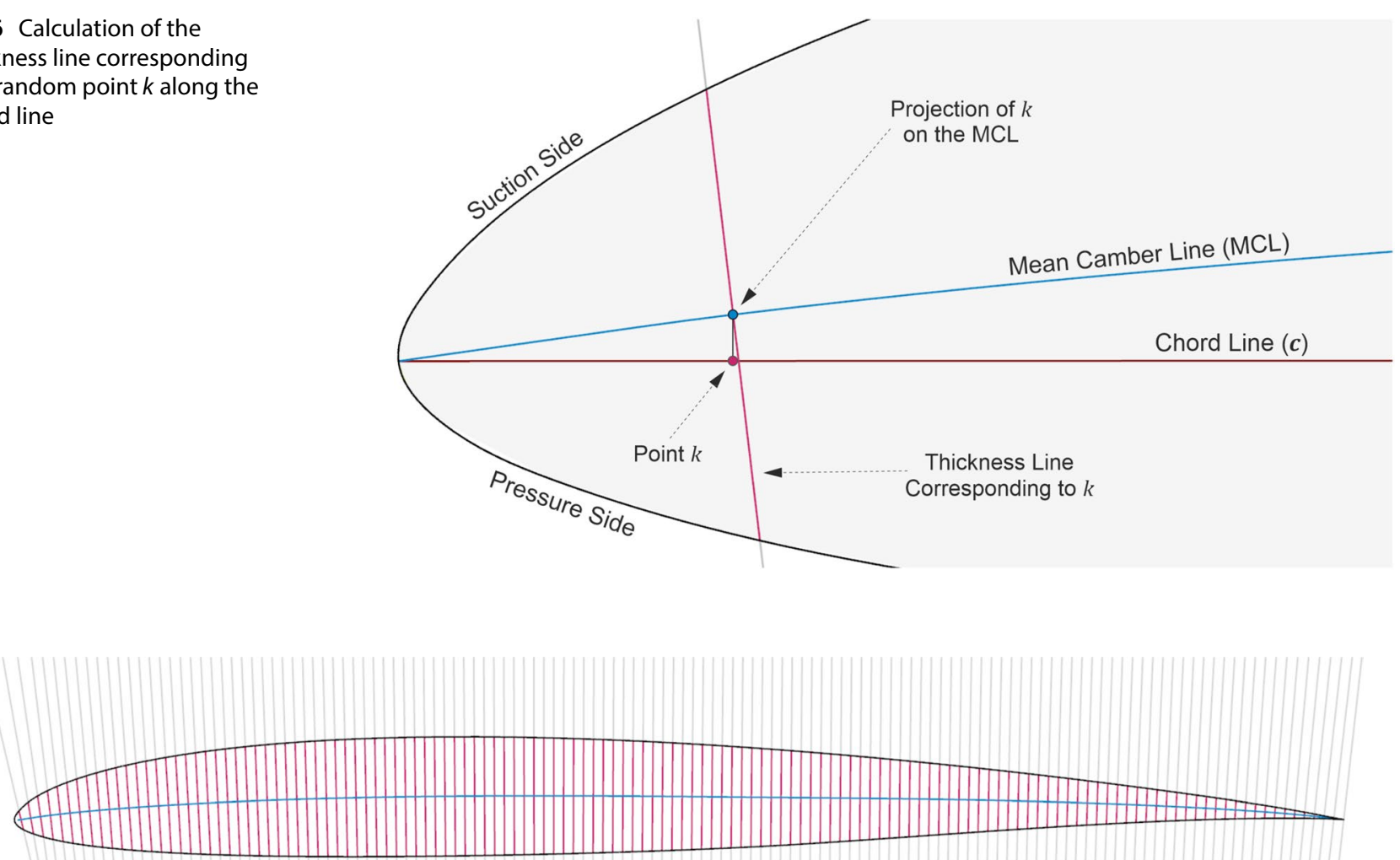

Fig. 7 Indicative thickness lines (magenta) of the RG15 airfoil

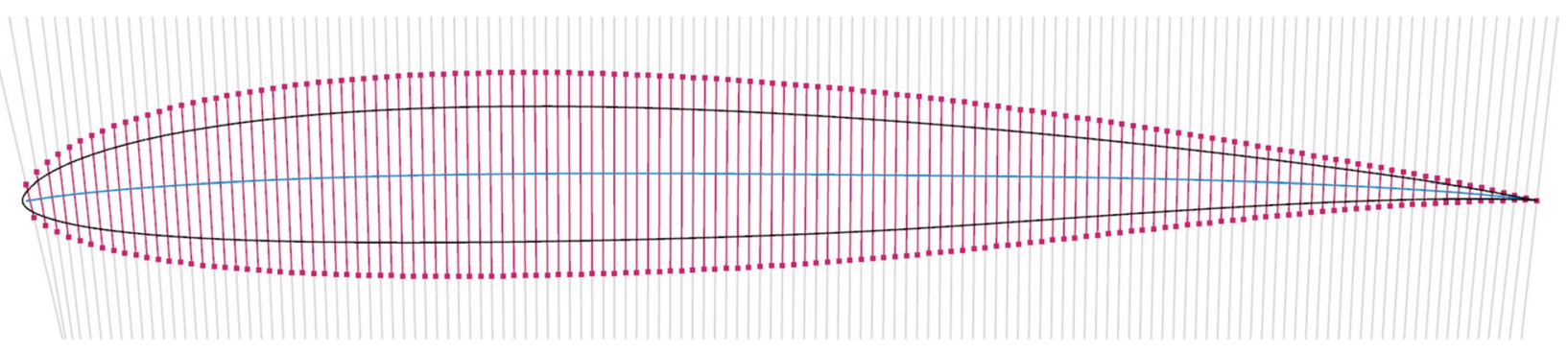

Fig. 8 Indicative points of a thickened airfoil, constructed through the proper extension of the RG15 thickness lines 
as a divergence from the ideal case. However, some early experiments $[24,25]$, which were carried out to determine the lift and drag dependence upon the trailing edge radius, revealed that a rounded trailing edge of radius less than $1 \%$ of the chord length produces essentially the same lift and drag as a maximally sharp trailing edge, while a notable increase in drag was observed for rounded trailing edges of radius above $2 \%$ of the chord length. In this context and given that the current blade manufacturing and transportation limitations do not allow sharp trailing edges to be constructed, the trailing edges of the original and thickened RG15 airfoils were locally thickened and rounded. For the generation of a blunt trailing edge without truncating the airfoil, QBlade software [26] provides the built-in Trailing Edge Gap function, where the desired gap and blending distance from the leading edge (i.e., the absolute percentage of the airfoil chord, downstream of which the smoothing code is free to modify the airfoil shape in order to accommodate the modified trailing edge) are specified as percentages of the chord length. Nevertheless, as it was observed during the utilization of the Trailing Edge Gap function, the user-defined blending distance was not being completely respected by the code; while additionally, the airfoil thickness was being measured and applied perpendicular to the center line (as utilized by QBlade instead of the actual $\mathrm{MCL}$ ), which is a rough and generally incorrect approximation of the MCL.

Therefore, in order to overcome the aforementioned shortcomings, a custom script was created within Grasshopper, to be used for the generation of a blunt trailing edge without truncating the airfoil, through the proper modification (local thickening) of the provided (baseline) airfoil geometry under consideration. As long as the features of the developed script are concerned, the user is permitted to precisely define the trailing edge diameter and blending distance from the leading edge as in QBlade, while conversely to QBlade, the airfoil thickness is measured and applied perpendicular to the airfoil's MCL, as it should be, so the resultant airfoil to have the exact same $M C L$ with the baseline, so as to retain its aerodynamic characteristics as far as possible. Once the baseline airfoil geometry (with a sharp trailing edge) and the required software parameters (blending distance and trailing edge diameter) have been provided, the modified airfoil geometry is constructed through the application of an additional parabolic thickness distribution to the baseline airfoil, starting from the point along the chord that corresponds to the established blending distance and ending at the airfoil's trailing edge; in such a way that the defined trailing edge diameter to be exactly achieved and the resultant airfoil geometry to fulfill all the required continuity, curvature and smoothness criteria. The blending distance and trailing edge diameter are schematically defined in Fig. 9.

In Fig. 10, an indicative application of the developed methodology described above to the RG15 airfoil is presented, where the trailing edge diameter and the blending distance from the leading edge were set equal to $1 \%$ and $50 \%$ of the chord length respectively.

As it seems, the baseline (RG15-black) and the modified (red) airfoil geometries coincide from the leading edge until the point that corresponds to the $50 \%$ of the chord, while the differentiation between the two airfoils lies only in the region downstream of the $50 \%$ of the chord; increasing smoothly and parabolically as the trailing edge is approached, to attain the desirable thickness. Subsequently, in order to create a rounded trailing edge geometry, a circle (black) is fitted to the thickened trailing edge of the modified airfoil, in such a way that is tangent to its upper and lower surfaces and passes through the sharp trailing edge of the baseline airfoil, as depicted in Fig. 10b; so as the reformed airfoil to have the same chord line with the baseline one. Finally, the leftover edges are properly cut off, to result in the final modified airfoil with a rounded trailing edge.

\section{RG15 airfoil family}

In this work the methodology, developed for the conversion of sharp trailing edges to rounded ones, was applied to all the original and thickened RG15-(xx) airfoils. For each one of the six airfoils (denoted as "parent" airfoils), four

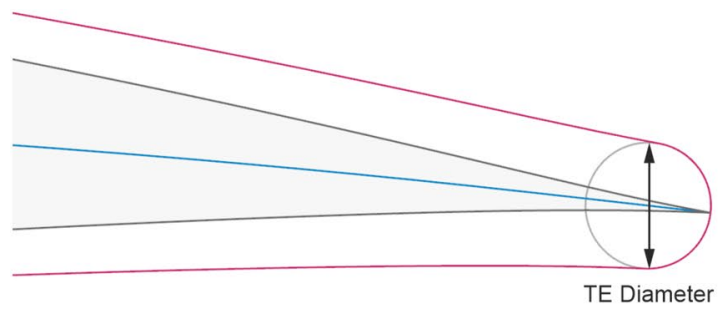

(a)

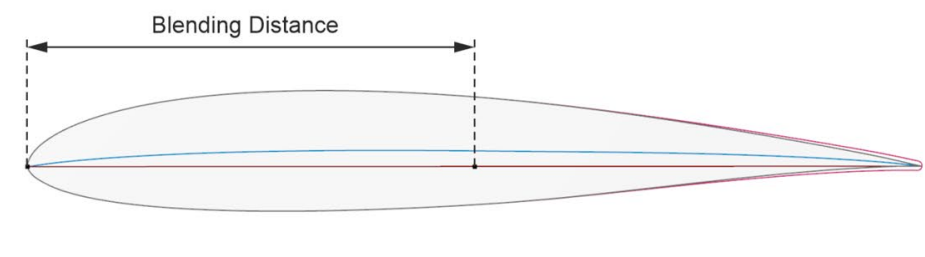

(b)

Fig. 9 Schematic definition of the $\mathbf{a}$ trailing edge diameter and $\mathbf{b}$ blending distance 
Fig. 10 Schematic representation of the followed methodology for the creation of a rounded trailing edge (a)

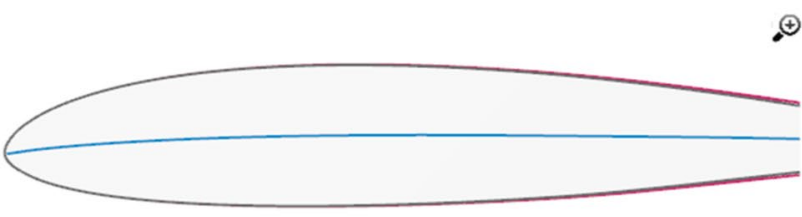

(b)

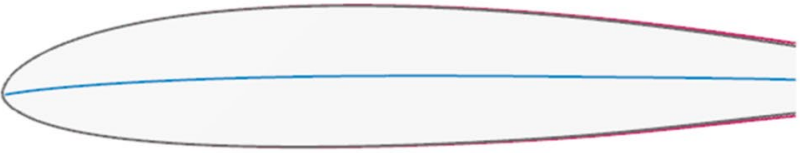

(c)

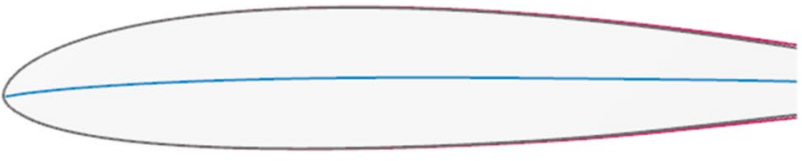

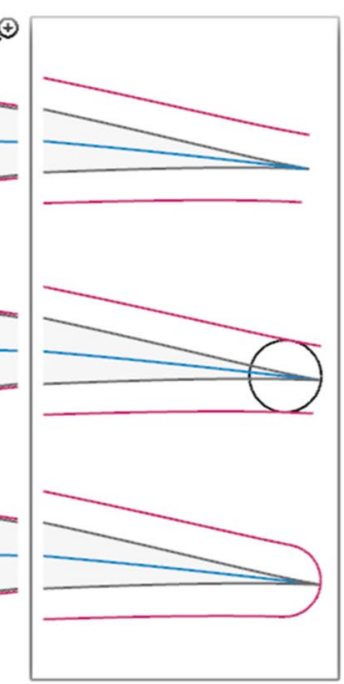

modified configurations were generated (Table 1), by setting the trailing edge radius equal to $0.5 \%$ of the chord length (i.e., trailing edge diameter equal to $1 \%$ ) and the blending distance equal to $0 \%, 50 \%, 60 \%$ and $70 \%$ of the chord length respectively. Regarding the notation used for the modified airfoils, the RG15-(xx)-yy-z refers to an airfoil with an increased thickness-to-chord ratio by $x x \%$ compared to the original RG15, whose rounded trailing edge was created by setting the trailing edge diameter equal to $z \%$ and the blending distance from the leading edge equal to yy $\%$ of the chord length.

The four variants for each one of the "parent" airfoils, corresponding to the different blending distance values, as well as their "parent" airfoil, were then evaluated using XFOIL software [27], at various low Reynolds numbers, in order to examine the influence of the blending distance parameter on the developed aerodynamic forces. Figure 11a illustrates the drag polar for the RG15, RG15(00)-00-1, RG15-(00)-50-1 and RG15-(00)-70-1 airfoils at $R e=300,000$. Apparently, no significant variation of the drag polar was detected with different values of the blending distance parameter, while the same outcome was observed by examining the rest of low Reynolds numbers considered during the experimental study at UIUC [14]. In addition, Fig. 11a indicates that the adoption of a rounded trailing edge (instead of a maximally sharp one) did not result in a substantial reduction in the aerodynamic performance of the airfoil, since the comparison between the drag polars (XFOIL solver) of RG15 and RG15-(00)-70-1 airfoils reveal a high level of similarity.

To further support the latter deduction, RG15 and RG15(00)-70-1 airfoils were also evaluated at $R e=300,000$, using a 2D RANS solver [28] instead of XFOIL; turbulence simulation was achieved by means of the standard twoequation Shear Stress Transport (SST) $k-\omega$ turbulence model. The comparison between the resultant drag polars is provided in Fig. $11 \mathrm{~b}$, verifying that a rounded trailing edge with a radius equal to $0.5 \%$ of the chord does not affect the aerodynamic performance of the airfoil to a large degree, as only minor differences were detected, especially in the upper high-drag region. The simulation parameters for both XFOIL and RANS solvers are equal to the ones adopted during the detailed evaluation of the entire RG15 airfoil family, which are presented in the following Sects. 6 and 7.

Consequently, since no significant impact of the blending distance parameter on the aerodynamic performance was found, the airfoils that were produced
Table 1 The modified RG15 airfoils with a thickened and rounded trailing edge

\begin{tabular}{llllll}
\hline \multicolumn{2}{l}{ "Parent" airfoils-sharp trailing edge } & & & \\
\hline RG15 & RG15-(10) & RG15-(20) & RG15-(30) & RG15-(40) & RG15-(50) \\
\hline Modified airfoils-rounded trailing edge & & & & \\
\hline RG15-(00)-00-1 & RG15-(10)-00-1 & RG15-(20)-00-1 & RG15-(30)-00-1 & RG15-(40)-00-1 & RG15-(50)-00-1 \\
RG15-(00)-50-1 & RG15-(10)-50-1 & RG15-(20)-50-1 & RG15-(30)-50-1 & RG15-(40)-50-1 & RG15-(50)-50-1 \\
RG15-(00)-60-1 & RG15-(10)-60-1 & RG15-(20)-60-1 & RG15-(30)-60-1 & RG15-(40)-60-1 & RG15-(50)-60-1 \\
RG15-(00)-70-1 & RG15-(10)-70-1 & RG15-(20)-70-1 & RG15-(30)-70-1 & RG15-(40)-70-1 & RG15-(50)-70-1 \\
\hline
\end{tabular}




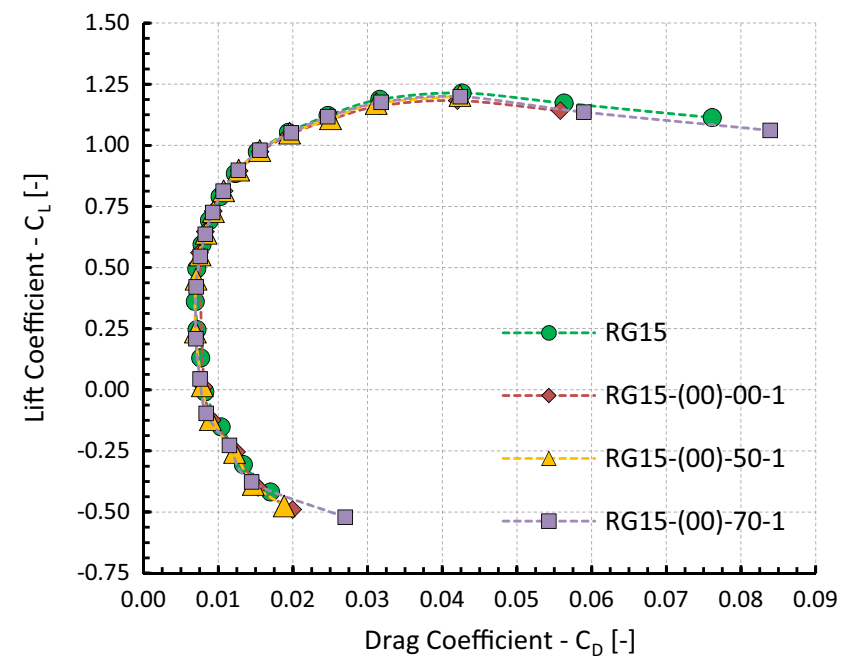

(a) XFOIL

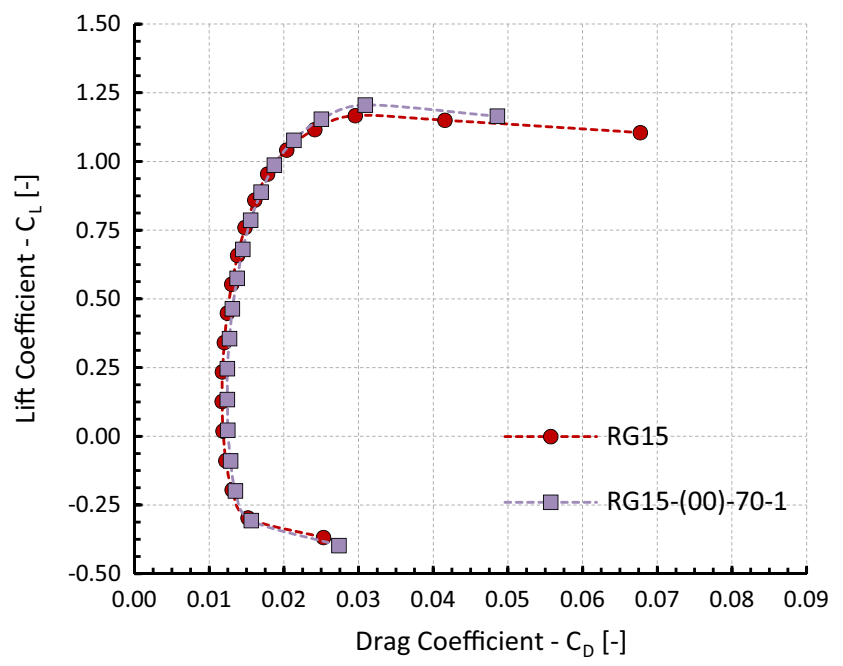

(b) 2D RANS (SST $k-\omega)$

Fig. 11 The influence of the rounded trailing edge and blending distance parameter on the drag polar at $R e=300,000$. a XFOIL results. $\mathbf{b} 2 \mathrm{D}$ RANS results

by setting the blending distance equal to $70 \%$ have been selected to form the RG15 airfoil family, as they are the ones with the lesser deviation from the "parent" airfoils. The final airfoil family RG15-(xx)-70-1 generated through this work is illustrated in Fig. 12, whereas

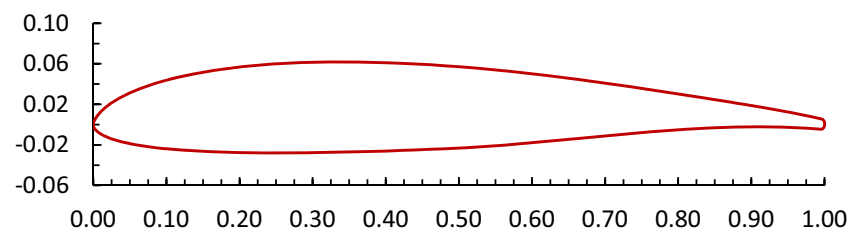

(a) RG15-(00)-70-1

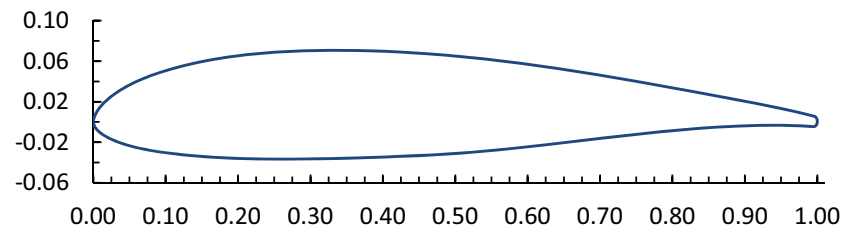

(c) RG15-(20)-70-1

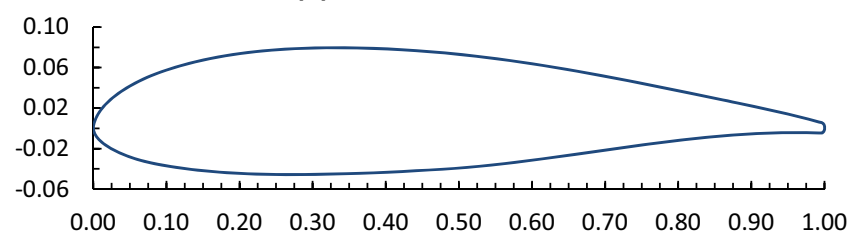

(e) RG15-(40)-70-1
Table 2 contains the major geometrical characteristics of the corresponding airfoils. Given that all the airfoils have been constructed using the same MCL (the MCL of the original RG15 airfoil), the maximum camber, the position of maximum camber and the position of maximum thickness are mutual for all members of the family.

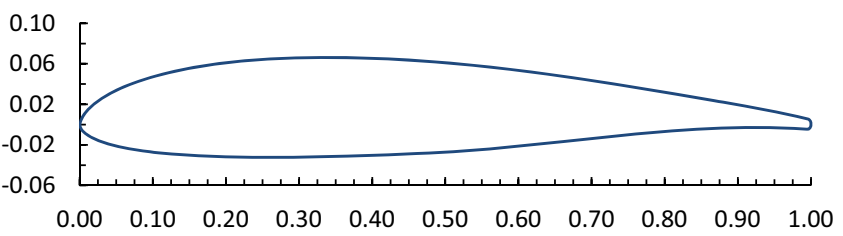

(b) RG15-(10)-70-1

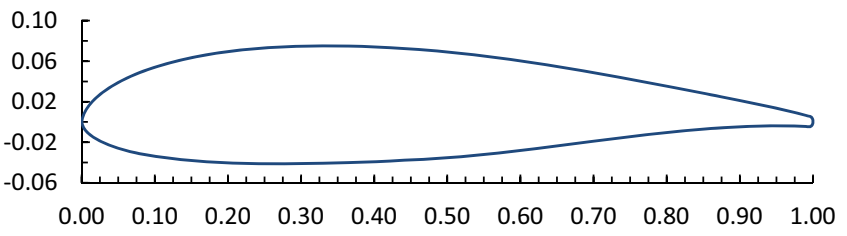

(d) RG15-(30)-70-1

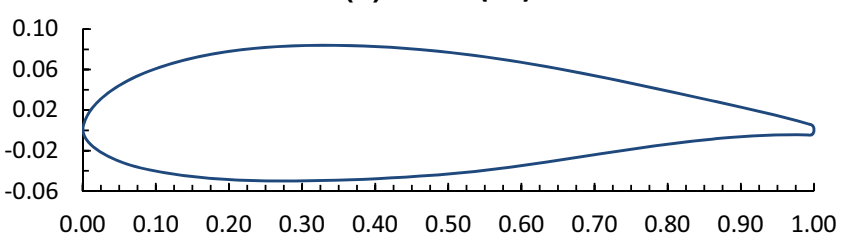

(f) RG15-(50)-70-1

Fig. 12 The airfoils composing the proposed RG15 airfoil family 
Table 2 Geometrical characteristics of the airfoils composing the proposed RG15 airfoil family

\begin{tabular}{llll}
\hline Airfoil & Max. thickness & Max. camber & Sectional area \\
\hline Original RG15 & $0.0892 c$ & $0.018 c$ & $0.0595 c^{2}$ \\
RG15-(00)-70-1 & $0.0892 c$ & $0.018 c$ & $0.0605 c^{2}$ \\
RG15-(10)-70-1 & $0.0981 c$ & $0.018 c$ & $0.0664 c^{2}$ \\
RG15-(20)-70-1 & $0.1070 c$ & $0.018 c$ & $0.0724 c^{2}$ \\
RG15-(30)-70-1 & $0.1160 c$ & $0.018 c$ & $0.0784 c^{2}$ \\
RG15-(40)-70-1 & $0.1249 c$ & $0.018 c$ & $0.0843 c^{2}$ \\
RG15-(50)-70-1 & $0.1338 c$ & $0.018 c$ & $0.0903 c^{2}$ \\
\hline
\end{tabular}

\section{XFOIL code}

The aerodynamic performance of the RG15 airfoils was initially evaluated by means of XFOIL software, which relies on the combination of a potential flow panel method with an integral boundary layer formulation, for the analysis of subsonic isolated airfoils [27]. The final solution is achieved through the implementation of an iterative procedure between the inner and outer flow solutions on the boundary layer displacement thickness, until an appropriate convergence criterion is reached; accordingly, the viscous pressure distributions (which capture the effects of laminar separation bubbles and trailing edge separation) can be predicted with reasonable accuracy [29]. During an XFOIL analysis, the transition from laminar to turbulent state is predicted by applying an approximate $e^{N}$ envelope method [30], according to which, only the most amplified frequency at a given point on the airfoil downstream from the point of instability is tracked (instead of tracking the

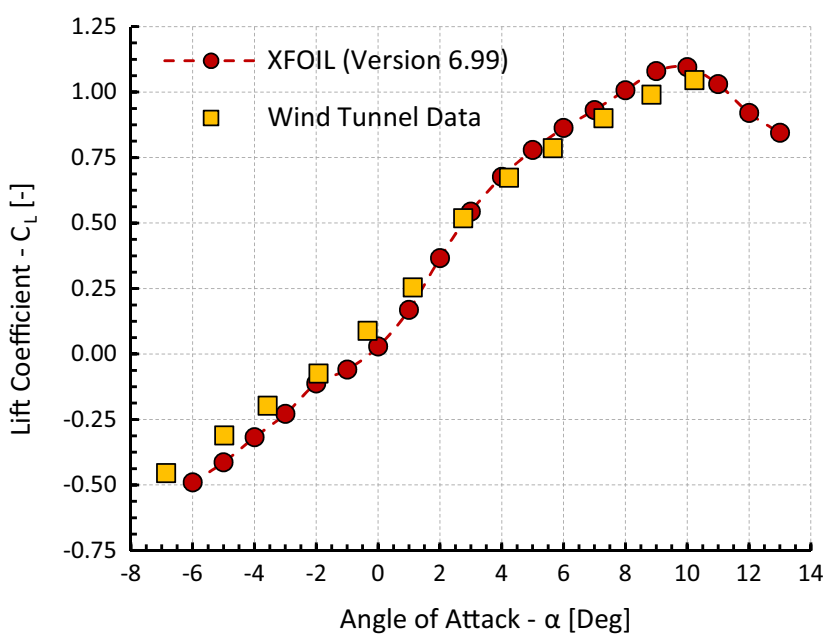

(a) amplification rates of all frequencies), in order to obtain the amplitude of the entire frequency envelope [29]. Transition is assumed when this integrated amplitude $N$ reaches an empirically determined value, denoted as $N_{\text {crit }}$. The appropriate value of $N_{\text {crit }}$ parameter can be calculated as a function of the absolute value of turbulence intensity, through Eq. (1) [31]:

$N_{\text {crit }}=-8.43-2.4 \ln \left(T_{u}\right)$.

\subsection{XFOIL setup and validation}

Prior to the aerodynamic evaluation of the proposed RG15 airfoil family, the accuracy of XFOIL was validated against the available experimental data for the original RG15 airfoil [14]. In this study, a value of 9 was adopted for $N_{\text {crit }}$ in order to match the turbulence levels reported during the wind tunnel testing (that is a turbulence intensity value less than 0.001 or $0.1 \%$ ) [14]. As long as the geometry description is concerned, the study of Morgado et al. [32] concluded that no significant variation in the aerodynamic coefficients should be detected by increasing the number of points (panel resolution) on the airfoil surface over 150 . However, XFOIL documentation advises that a fine panel resolution is required, if the appearance of laminar separation bubbles is expected. To this end, 300 points were used to describe the RG15 airfoil geometry, by applying a denser point distribution near the leading and trailing edges. The Mach number was set to zero.

Figures 13 and 14 provide the lift and drag coefficients of the RG15 airfoil, as a function of the angle of attack, for $R e=60,000$ and $R e=300,000$ respectively, as they

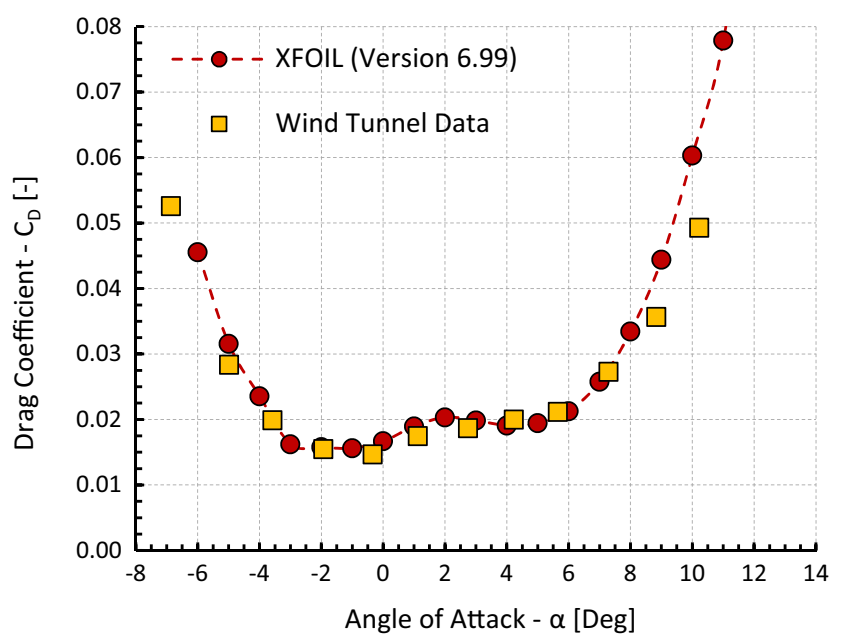

(b)

Fig. 13 Comparison of the XFOIL results for the lift and drag coefficients of the original RG15 airfoil at $R e=60,000$ with the corresponding experimental measurements [14]; $\mathbf{a} C_{L}-\alpha . \mathbf{b} C_{D}-\alpha$ 


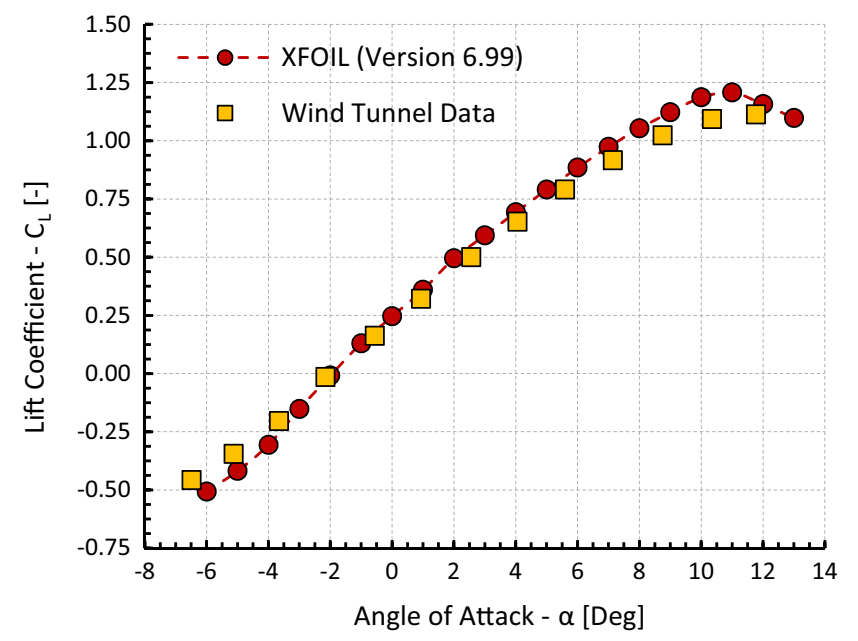

(a)

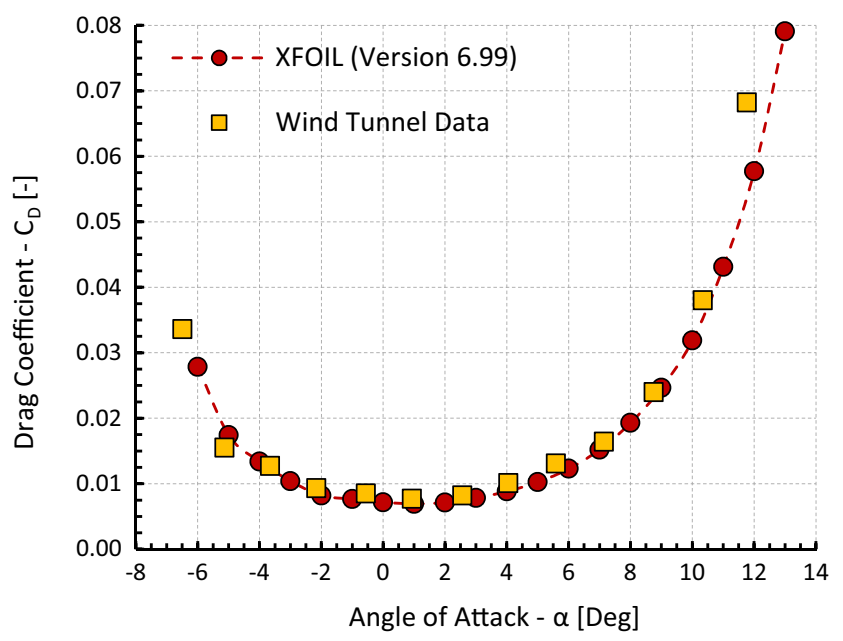

(b)

Fig. 14 Comparison of the XFOIL results for the lift and drag coefficients of the original RG15 airfoil at $R e=300,000$ with the corresponding experimental measurements [14]; $\mathbf{a} C_{L}-\alpha \cdot \mathbf{b} C_{D}-\alpha$

resulted from both the testing program at the UIUC lowturbulence subsonic wind tunnel [14] and XFOIL software; the particular Reynolds numbers correspond to the lower and upper values of the Reynolds number spectrum examined during the experimental studies at UIUC [14].

As it can be observed, the experimental lift and drag curves have been predicted with reasonable accuracy for both Reynolds numbers; similar levels of accuracy were found during the comparisons made for the rest of the available experimental data, corresponding to the different Reynolds numbers (within the particular range) that were examined during the experimental study at UIUC [14]. However, some notable discrepancies between the experimental and numerical results were also detected, especially in terms of the drag coefficient. In particular, XFOIL seems to over-predict the drag coefficient at $R e=60,000$ for angles of attack higher than $8^{\circ}$, while an evident under-prediction of the drag coefficient at $R e=300,000$ was also observed, regarding the angles of attack higher than $10^{\circ}$. Nevertheless, the approximation of the experimental data is considered acceptable, since the trend and major aspects of both curves have been well captured. Consequently, XFOIL can be used for the evaluation of the RG15 airfoil family within the particular low Reynolds numbers range.

\section{RANS solver}

Apart from the XFOIL analysis, the aerodynamic performance of the entire RG15 family was further evaluated by means of an in-house 2D RANS solver, so as to have a better understanding of the respective flow fields and the associated phenomena. The particular flow solver is based on a dimensionless formulation of the Navier-Stokes equations, modified by the artificial compressibility method [28]; space discretization is based on node-centered Finite Volume formulation, utilizing a $2^{\text {nd }}$ order MUSCL (Monotonic Upstream Scheme for Conservation Laws) scheme; turbulence simulation is succeeded through the standard two-equation Shear Stress Transport (SST) $k-\omega$ turbulence model [33], which is a combination of the $k-\varepsilon$ and $k-\omega$ turbulence models. The SST $k-\omega$ model was preferred over the alternative two-equation turbulence models because of the beneficial features that provides, since it combines the advantages of both $k-\varepsilon$ and $k-\omega$ models, while disregarding their major shortcomings [34]. Furthermore, according to the study on Morgado et al. [32], the SST $k-\omega$ model seems capable of accurately predicting a wide spectrum of low Reynolds number flows over airfoils. The limitations of this approach should be taken into account, as no transition model or low-Re corrections are considered in this study. The spatial discretization of the flow and turbulence models is performed over two-dimensional unstructured grids, comprised of both triangular and quadrilateral elements, along with a nodecentered finite-volume scheme. A detailed description of the employed solver can be found in the work of Leloudas et al. [28].

\subsection{CFD setup and validation}

Prior to the aerodynamic evaluation of the RG15 airfoil family, the ability of the 2D RANS solver to accurately predict the lift and drag forces was validated against the available experimental data for the original RG15 airfoil 
[13]. However, a grid independence study was also performed before the validation study, in order to guarantee that the grid resolution does not affect the simulation results. For this purpose, three computational grids with different resolutions were constructed, denoted as Mesh 1 (coarse), Mesh 2 (medium) and Mesh 3 (fine), by considering an angle of attack equal to $0^{\circ}$. At this point, it is noted that the desired angle of attack for each flow simulation was achieved by properly rotating the airfoil geometry instead of changing the inflow angle; then the updated computational domain was re-meshed. Therefore, a different computational grid was constructed for each one of the considered airfoils and angles of attack. This procedure was adopted in order to retain a high grid density in the wake region for all different angles of attack.

All three grids were generated by adopting a computational domain, such as the one depicted in Fig. 15a, in which the inflow boundary was placed at a distance of 25 chord lengths upstream the airfoil's leading edge and the outflow boundary at a distance of 40 chord lengths downstream the airfoil's trailing edge. Mesh 1 (which is the coarsest among the examined ones) was composed by 164,345 triangular and 25,284 quadrilateral elements, with a total number of nodes equal to 107,927 . For the description of the airfoil geometry 602 points were used along the airfoil surface, by applying a denser distribution near the leading and trailing edges. Mesh 2 was constructed by applying a denser points distribution on the airfoil surface ( 804 points), accompanied by increasing mesh resolution within the entire computational domain; it comprises of 380,032 triangular and 28,140 quadrilateral elements, with a total number of nodes equal to 218,765 . Finally, an even finer mesh resolution and denser points distribution on the airfoil surface was adopted for the construction of Mesh 3, which is composed by 686,556 triangular and 47,920 quadrilateral elements, with a total number of nodes equal to 392,160 . The wall spacing of the first inflation layer, created on the airfoil surface for all the three grids, was calculated by considering a $\mathrm{y}^{+}$value of approximately 1 . The corresponding meshing parameters are also provided in Table 3.

Table 4 presents the numerical lift and drag coefficients of the RG15 airfoil at $R e=300,000$ and $\alpha=0^{\circ}$, as obtained by using Mesh 1, Mesh 2 and Mesh 3. Apparently, no significant variation of the lift and drag coefficients was found by increasing the mesh resolution over the levels provided by Mesh 2; the percentage difference in both lift and drag obtained through the utilization of Mesh 2 and Mesh 3 was below $0.3 \%$, even though the number of nodes has been almost doubled. Therefore, the resolution provided by Mesh 2 is considered sufficient to result in a mesh independent solution. Consequently, a computational mesh of analogous resolution was constructed for each one of the different angles of attack that were encountered during this validation study. Such a computational mesh is presented in Figs. 15b and 16.

The RANS simulations were conducted at $R e=300,000$ for angles of attack ranging from $-6^{\circ}$ to $12^{\circ}$ (using an

Table 3 Meshing parameters used for the grid independence study

\begin{tabular}{llll}
\hline Mesh parameter & Mesh 1 & Mesh 2 & Mesh 3 \\
\hline Number of nodes & 107,927 & 218,765 & 392,160 \\
Triangular elements & 164,345 & 380,032 & 686,556 \\
Quadtrilateral Elements & 25,284 & 28,140 & 47,920 \\
Points on airfoil & 602 & 804 & 1200 \\
Target $^{+}$ & $\approx 1.0$ & $\approx 1.0$ & $\approx 1.0$ \\
\hline
\end{tabular}

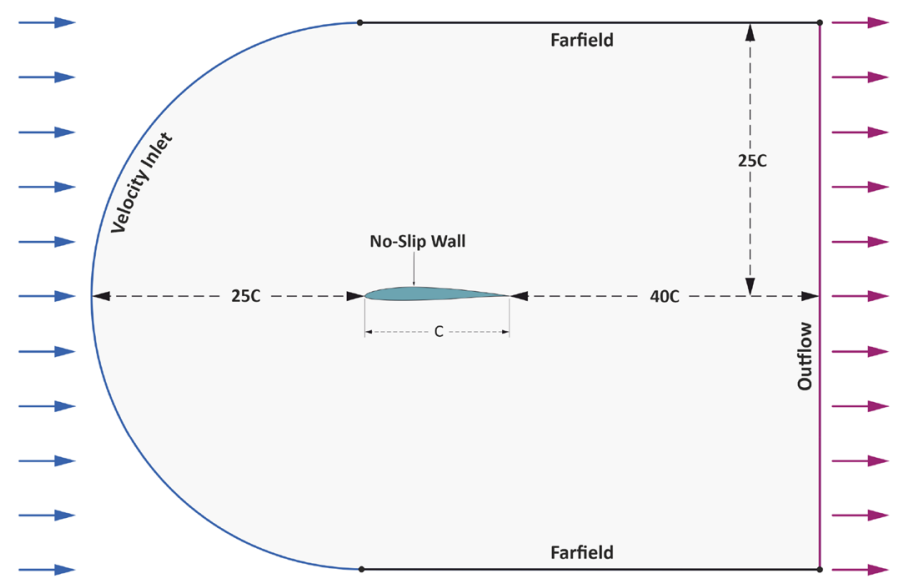

(a)

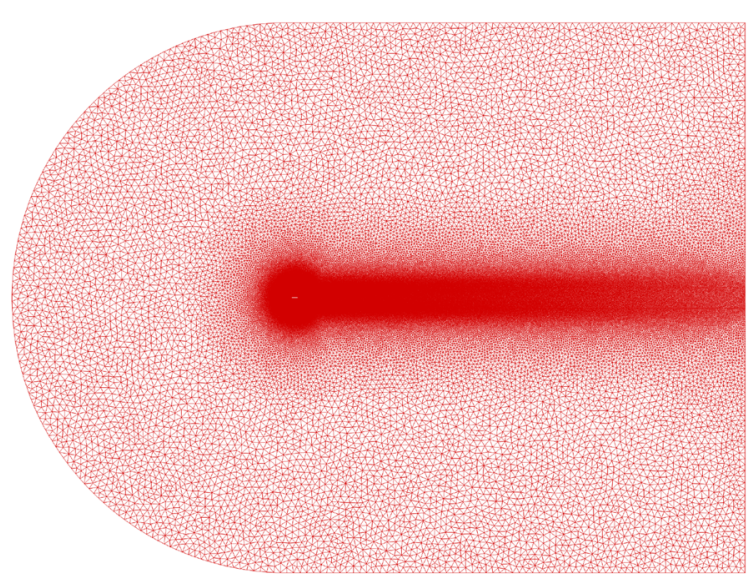

(b)

Fig. 15 a The computational domain used for the validation study of the RANS solver, $\mathbf{b}$ wide view of the corresponding computational grid 
increment of $1^{\circ}$ ); therefore, 19 computational grids were constructed in total. In Fig. 17, the lift and drag coefficients of the RG15 airfoil as a function of the angle of attack are illustrated, as obtained from the testing program at the UIUC low-turbulence subsonic wind tunnel [14], XFOIL code and the 2D RANS solver. As it seems, the trend of both experimental curves have been well predicted by the RANS solver; however, an over-prediction of the drag coefficient was observed (typical characteristic of the SST $k-\omega$ turbulence model), especially for the angles of attack lying between $-3^{\circ}$ and $6^{\circ}$. According to the results presented in the study of Morgado et al. [22], a better match of the experimental drag coefficients could be achieved by the utilization of low Reynolds number correction to the standard SST $k-\omega$
Table 4 The results of the grid independence study. The flow simulations were performed for RG15 airfoil at $R e=300,000$ and $\alpha=0^{\circ}$

\begin{tabular}{llllll}
\hline & Number of nodes & $C_{L}$ & $C_{D}$ & $\begin{array}{l}\text { Percentage } \\
\text { Diff. } C_{L}(\%)\end{array}$ & $\begin{array}{l}\text { Percentage } \\
\text { Diff.- } C_{D} \\
(\%)\end{array}$ \\
\hline Mesh1 & 107,927 & 0.2355460 & 0.0117844 & - & - \\
Mesh 2 & 218,765 & 0.2353327 & 0.0116944 & 0.09 & 0.76 \\
Mesh 3 & 392,160 & 0.2353510 & 0.0116699 & 0.01 & 0.21 \\
\hline
\end{tabular}

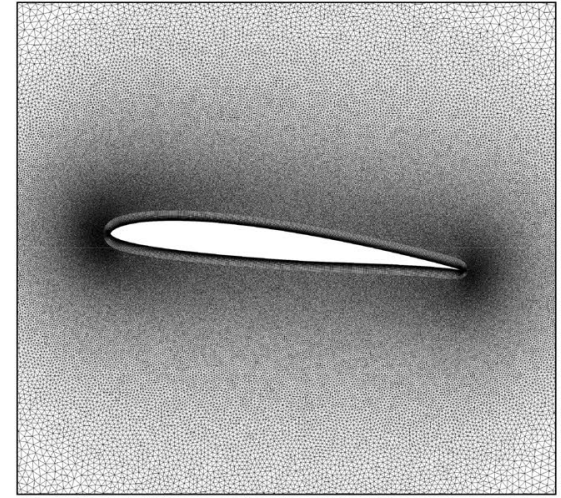

(a)

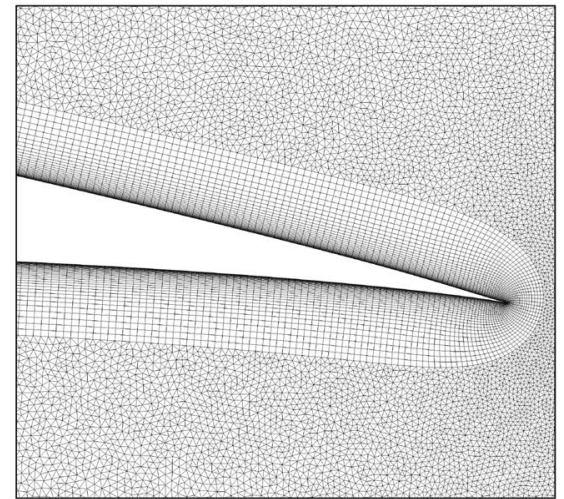

(b)

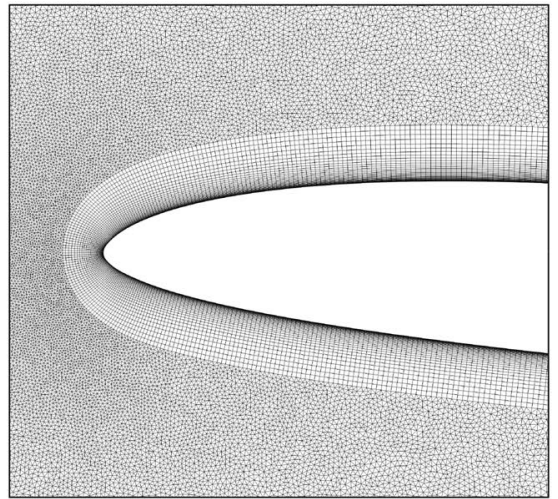

(c)

Fig. 16 The hybrid computational grid used for the flow field simulation of the original RG15 airfoil at $\alpha=6^{\circ}$

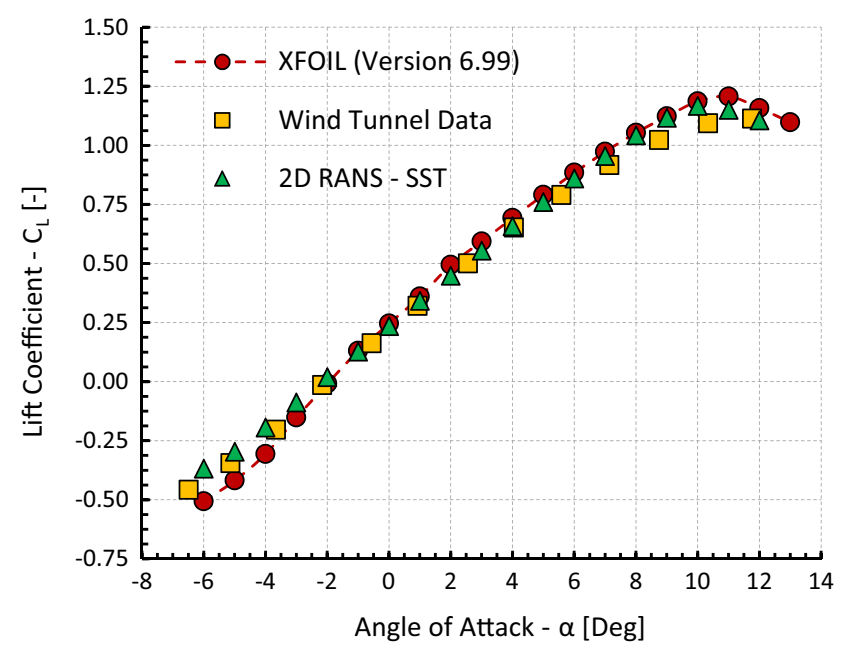

(a)

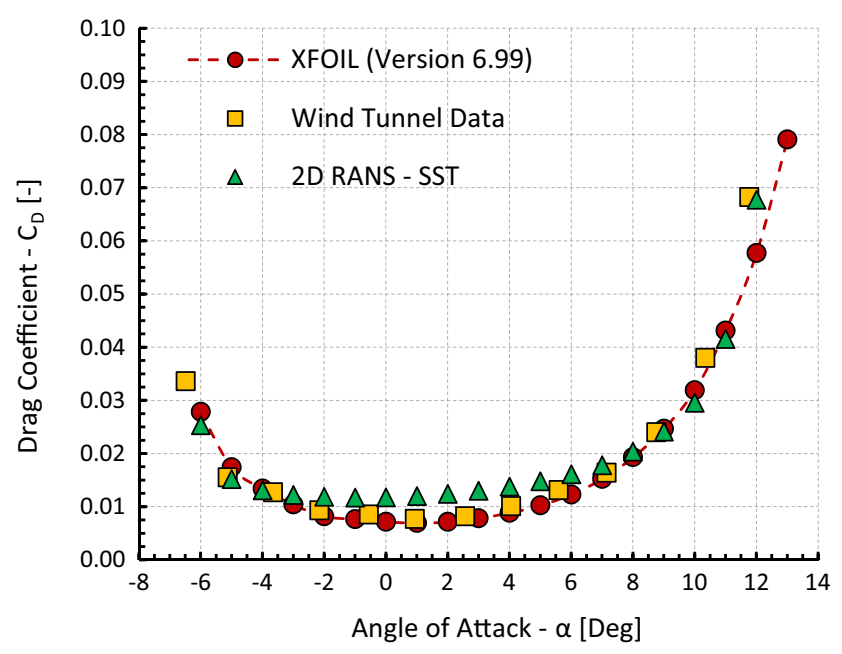

(b)

Fig. 17 The lift and drag coefficients of the original RG15 airfoil at $R e=300,000$, as obtained by XFOIL software, the 2D RANS solver and the experimental measurements [14] 
turbulence model. However, the implementation of such a modified turbulence model is the subject of ongoing work.

\subsection{Lift and drag calculation}

The components of the total aerodynamic force $\boldsymbol{R}=\left(R_{x}, R_{y}\right)$ on the airfoil are calculated by integrating the pressure $(p)$ and shear stress $(\tau)$ distributions over the airfoil contour $\left(C_{s}\right)$ [35]

$R_{x}=-\oint_{C_{s}} p n_{x} d s+\oint_{C_{s}}\left(\tau_{x x} n_{x}+\tau_{x y} n_{y}\right) d s$,

$R_{y}=-\oint_{C_{s}} p n_{y} d s+\oint_{C_{s}}\left(\tau_{x y} n_{x}+\tau_{y y} n_{y}\right) d s$,

Regarding Eqs. (2) and (3), $n_{x}$ and $n_{y}$ denote the components of the unit vector $\hat{n}$ normal to the airfoil surface; $\tau_{x x}$, $\tau_{x y}, \tau_{y x}$ and $\tau_{y y}$ represent the components of the viscous stress tensor. Subsequently, the lift and drag forces on the airfoil can be obtained through the following equations [35]

$L=R_{y} \cos (\varphi)-R_{x} \sin (\varphi)$,

$D=R_{x} \cos (\varphi)+R_{y} \sin (\varphi)$,

where $\varphi$ is the angle between the inflow velocity vector and the $x$ axis. In this study, $\varphi$ angle is zero, since the desired angle of attack is simulated by rotating the airfoil geometry. Eventually, the lift and drag coefficients are calculated as follows [35]

$C_{L}=2 L / \rho V_{\infty} C$,

$C_{D}=2 D / \rho V_{\infty} C$,

where $\rho$ represents the air density, $V_{\infty}$ the ambient wind speed and $c$ the airfoil chord.

\section{Results and discussion}

\subsection{XFOIL results}

Similarly to the preceding validation study, the analysis of RG15 airfoil family was performed by setting the value of $N_{\text {crit }}$ parameter equal to 9 and Mach number equal to 0 , while the same panel resolution was adopted (300 points on each airfoil surface). The aerodynamic performance of the proposed RG15 airfoil family was evaluated for each one of the Reynolds numbers examined during the wind tunnel experiments [14], by considering a range of angles of attack between $-6^{\circ}$ and $20^{\circ}$. Table 5 contains the maximum lift-to-drag ratio $(L / D)_{\max }$ and the maximum lift coefficient $C_{L_{\text {max }}}$ for the RG15 airfoil and the entire RG15 airfoil family at the corresponding Reynolds numbers, ranging from $R e=60,000$ to $R e=300,000$. Apparently, the decrease of Re results in the reduction of $(L / D)_{\max }$ for each one of the examined airfoils, while for a fixed Re value, a reduction in $(L / D)_{\max }$ was also detected by increasing the thickness distribution. Therefore, all airfoils of the RG15 family exhibit a $(L / D)_{\max }$ loss, for every $R e$, as compared with the original RG15 airfoil. However, the percentage loss of $(L / D)_{\max }$ between a thickened and the original RG15 airfoil seems to decrease with increasing Re. In particular, the maximum reduction in $(L / D)_{\max }$ was found for the RG15-(50)-70-1 airfoil at $R e=60,000$; it was equal to $12.68 \%$. The corresponding reduction at $R e=300,000$ was equal to $4.13 \%$, while the percentage reductions for the rest of Reynolds numbers lie within the range defined by the aforementioned values. Apparently, the particular range decreases as the thickness-to-chord ratio is reduced. For example, the reduction in the maximum lift-to-drag ratio for the RG15-(30)-70-1 airfoil was found equal to $7.52 \%$ and $2.09 \%$, at $R e=60,000$ and $R e=300,000$ respectively. Conclusively, the impact of thickness distribution on the maximum lift-to-drag ratio tends to deteriorate as the Re increases.

RG15-(50)-70-1 airfoil demonstrated the maximum reduction in $(L / D)_{\max }$ at $R e=60,000$ (Table 5) because
Table 5 The maximum lift coefficient and lift-to-drag ratio for each one of the examined airfoils, at various Reynolds numbers, resulting from the XFOIL analysis

\begin{tabular}{|c|c|c|c|c|c|c|c|c|c|c|}
\hline \multirow[t]{2}{*}{ Airfoil } & \multicolumn{2}{|l|}{$60,000 \mathrm{Re}$} & \multicolumn{2}{|c|}{$100,000 \mathrm{Re}$} & \multicolumn{2}{|c|}{$150,000 \mathrm{Re}$} & \multicolumn{2}{|c|}{$200,000 \mathrm{Re}$} & \multicolumn{2}{|c|}{$300,000 \mathrm{Re}$} \\
\hline & $(L / D)_{\max }$ & $C_{L_{\max }}$ & $(L / D)_{\max }$ & $C_{L_{\max }}$ & $(L / D)_{\max }$ & $C_{L_{\max }}$ & $(L / D)_{\max }$ & $C_{L_{\max }}$ & $(L / D)_{\max }$ & $C_{L_{\max }}$ \\
\hline Original RG15 & 39.89 & 1.088 & 52.57 & 1.133 & 62.38 & 1.162 & 68.88 & 1.169 & 78.39 & 1.207 \\
\hline RG15-(00)-70-1 & 39.50 & 1.073 & 52.38 & 1.109 & 62.01 & 1.139 & 69.22 & 1.155 & 78.28 & 1.195 \\
\hline RG15-(10)-70-1 & 38.88 & 1.127 & 51.53 & 1.167 & 61.58 & 1.203 & 68.28 & 1.213 & 77.57 & 1.252 \\
\hline RG15-(20)-70-1 & 38.05 & 1.162 & 50.52 & 1.218 & 60.93 & 1.243 & 67.51 & 1.258 & 77.03 & 1.289 \\
\hline RG15-(30)-70-1 & 36.89 & 1.220 & 49.92 & 1.274 & 60.12 & 1.284 & 67.06 & 1.293 & 76.75 & 1.319 \\
\hline RG15-(40)-70-1 & 35.91 & 1.222 & 49.09 & 1.276 & 59.29 & 1.293 & 66.49 & 1.304 & 76.00 & 1.342 \\
\hline RG15-(50)-70-1 & 34.83 & 1.250 & 48.24 & 1.302 & 58.44 & 1.324 & 65.53 & 1.325 & 75.15 & 1.351 \\
\hline
\end{tabular}


this is the airfoil with the maximum geometrical deviation (thickness) from the original RG15 airfoil (compared to all the airfoils in the family) and the Reynold number is low enough to considerably affect the drag production. The $(L / D)_{\max }$ for all the examined airfoils is observed in the range of angle of attack ( $a$ ) between (approximately) $3^{\circ}$ and $7^{\circ}$. At this range of $a$, lift is not affected by the increase in maximum thickness of the airfoil, for constant Re (Figs. 18a, 19a). However, drag is increased with increasing the maximum airfoil thickness and decreasing $R e$ (Figs. 18b, 19b). At this Re range, as the Re decreases below 100,000 there is an increase in drag, particularly because of premature flow separation and failure to reattach, resulting in a reduced drag bucket and a large decrease in lift [36]. At $R e$ in the range between 50,000 and 100,000 the separation bubble and turbulent boundary-layer thickness

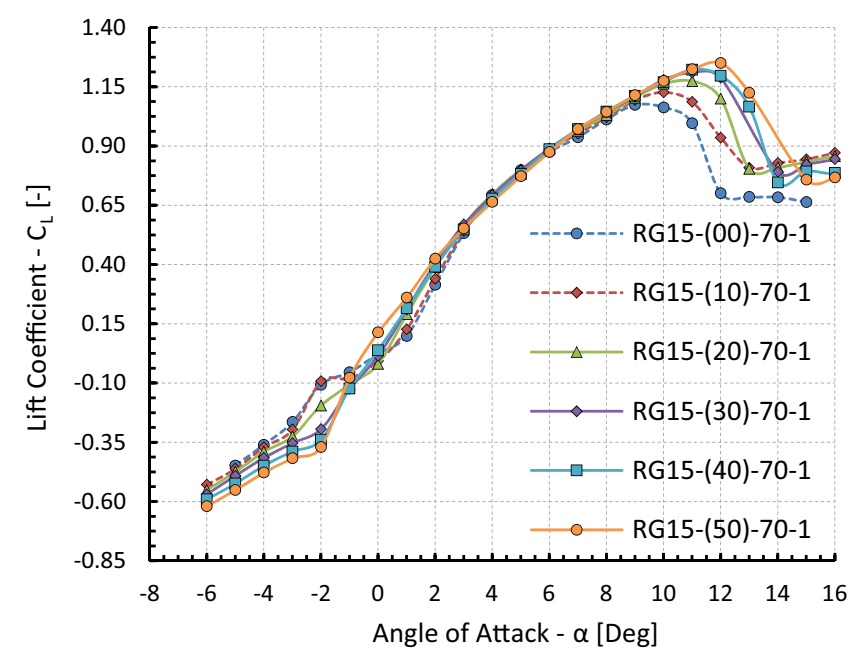

(a)

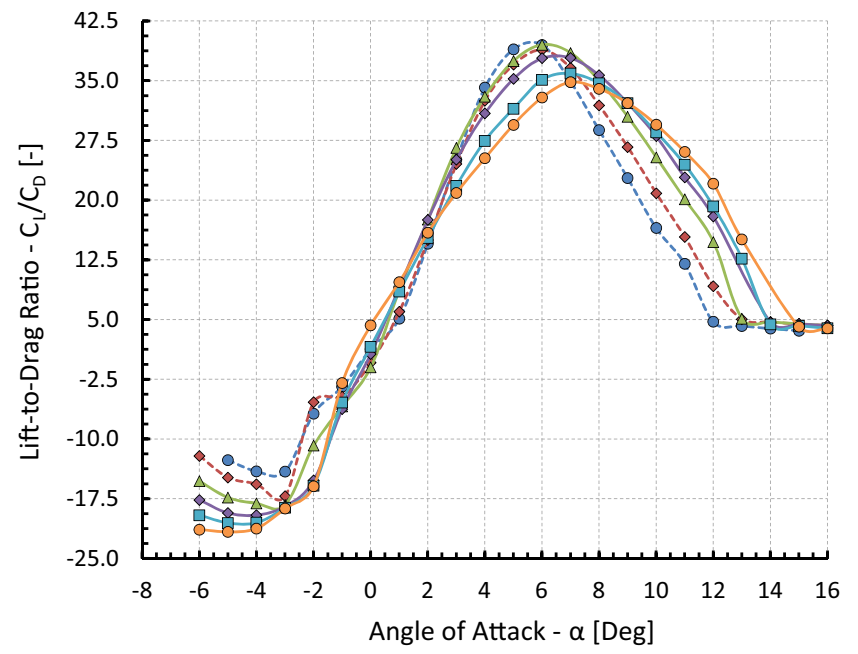

(c) both increase in size (compared to higher $R e$ ), a consequence of the higher contribution of the viscous forces, resulting in increased parasitic drag [36]. Nevertheless, at such low $R e$, the increase in airfoil thickness results in considerable increase in form drag, due to trailing edge separation, while simple flat plates outperform conventional airfoils for Re lower than 50,000 [36].

Although the thickening of the RG15 airfoil results in reduced maximum glide ratios, an opposite behaviour was observed for the maximum lift coefficient, which seems to increase by increasing the thickness-to-chord ratio, for a fixed Re value. Apart from Table 5, the particular effect is characteristically demonstrated in Figs. 18a and 19a, which provide the lift coefficient for the entire RG15 airfoil family, as a function of the angle of attack. Additional information about the behaviour of $(L / D)_{\max }$ and $C_{L_{\max }}$ with $R e$

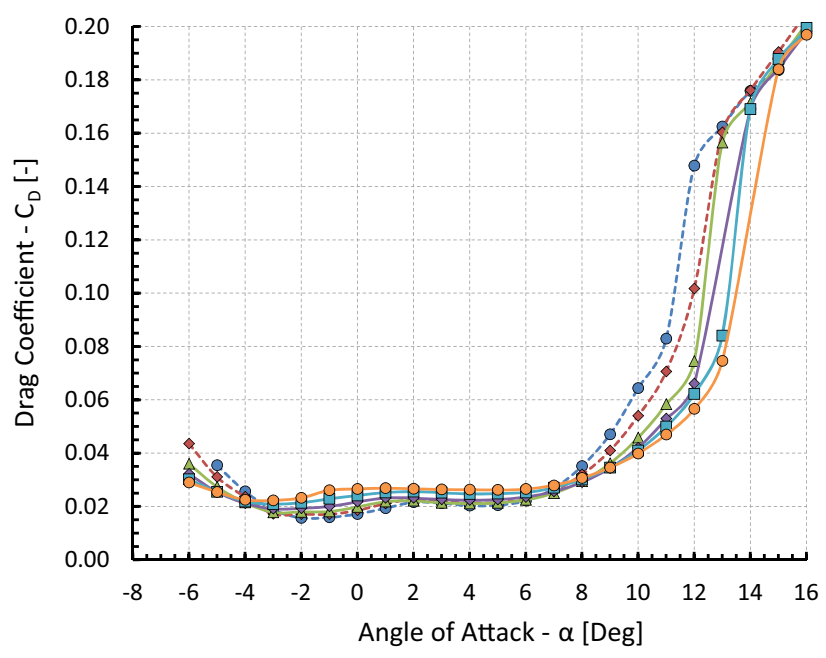

(b)

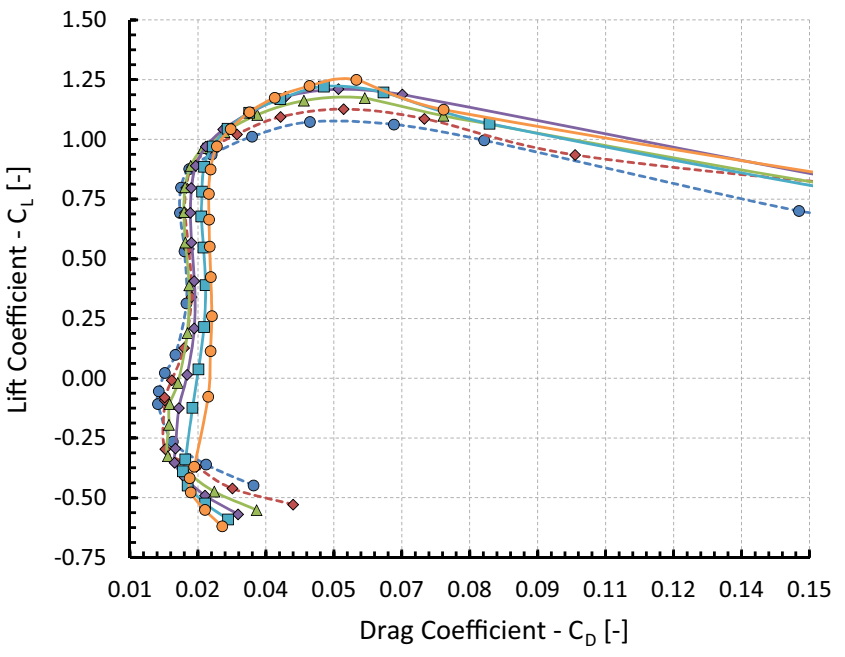

(d)

Fig. 18 Aerodynamic characteristics of the RG15 airfoil family at $R e=60,000$, as obtained through the XFOIL analysis. a $C_{L}-\alpha$. b $C_{D}-\alpha$. C $C_{L} / C_{D}-\alpha \cdot \mathbf{d} C_{L}-C_{D}$ 


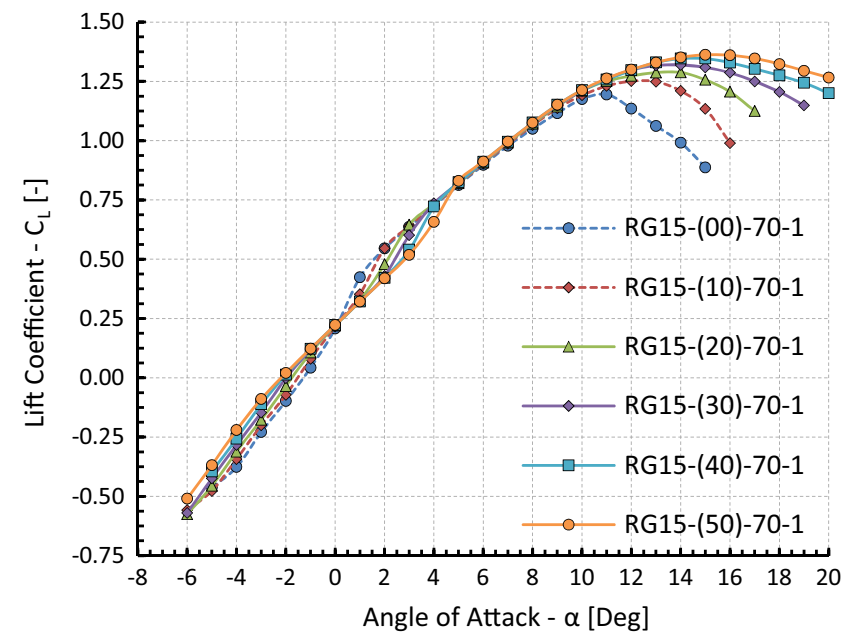

(a)

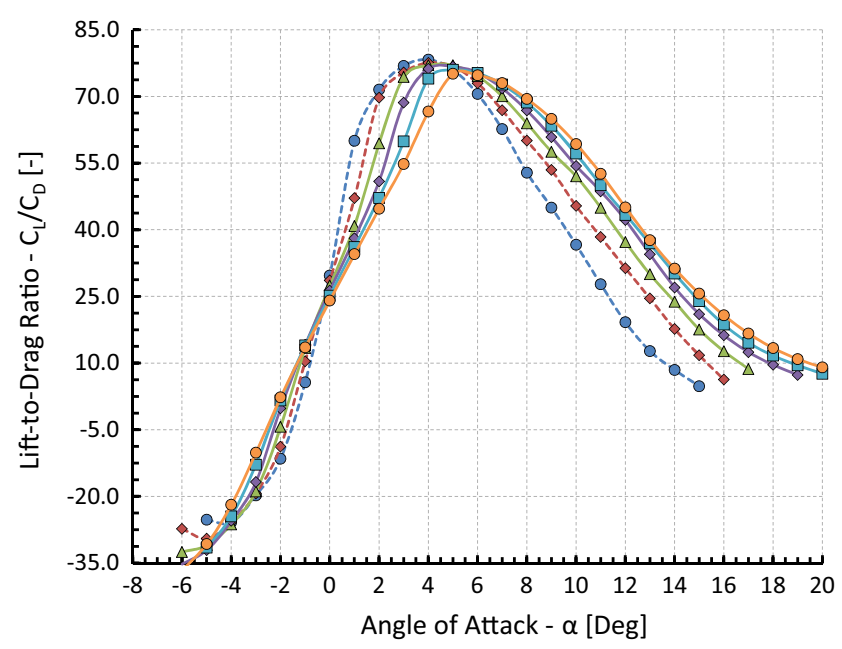

(c)

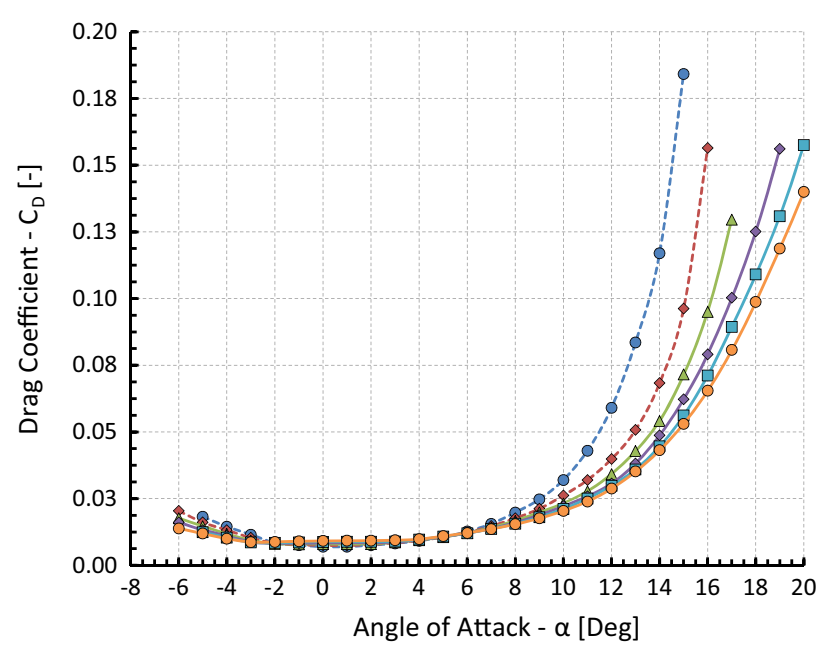

(b)

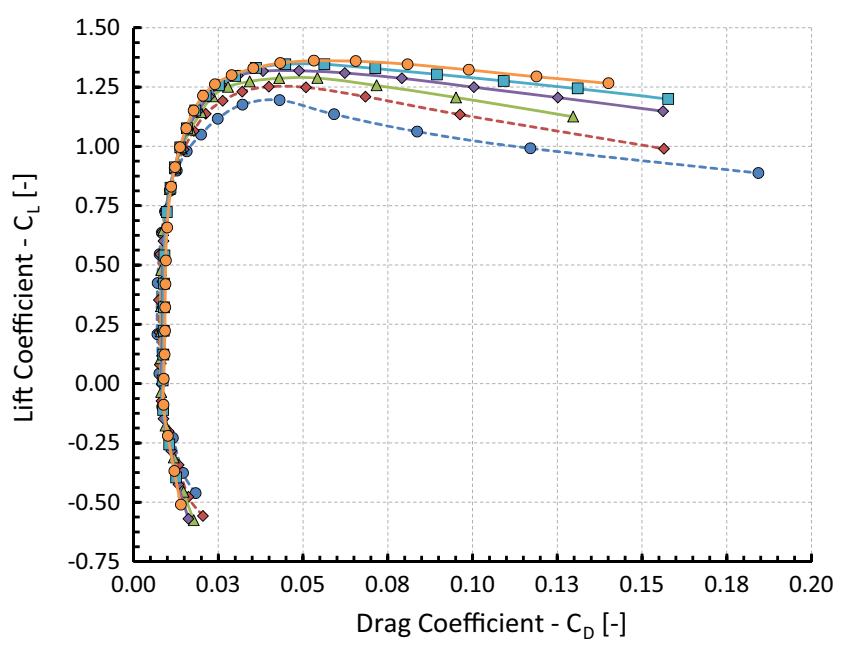

(d)

Fig. 19 Aerodynamic characteristics of the RG15 airfoil family at $R e=300,000$, as obtained through the XFOIL analysis. a $C_{L}-\alpha$. b $C_{D}-\alpha$. c $C_{L} / C_{D}-\alpha \cdot \mathbf{d} C_{L}-C_{D}$

can be obtained by observing Table 6 , which presents the increase rate of $(L / D)_{\max }$ and $C_{L_{\max }}$ due to the increase of Re (i.e., the rate of change in $(L / D)_{\text {max }}$ and $C_{L_{\text {max }}}$ as Re changes) for each airfoil of the RG15 family, using the slope of the linear regression line through data points suggested in $[37,38]$. According to Table 6, Re has a higher impact on $(L / D)_{\max }$ as the relative thickness of the airfoil increases. Unfortunately, such a conclusion cannot be drawn for $C_{L_{\text {max }}}$ since the slope of the linear regression line for $C_{L_{\max }}$ is not a monotonic function of the relative thickness.
Furthermore, an extension of the high-lift region to higher angles of attack has been also detected for both $R e=60,000$ and $R e=300,000$, while the increase of the thickness distribution leads to a smoother stall behavior, especially at $R e=300,000$. This latter deduction is further supported by observing the performance of the entire RG15 airfoil family in terms of the drag coefficient, which is represented in Figs. 18b and 19b. Even though the drag coefficient at $R e=60,000$ is analogous to the airfoil thickness for the angles of attack ranging from $-3^{\circ}$ to $7^{\circ}$, an

Table 6 Increase rate of $(L / D)_{\max }$ and $C_{L_{\max }}$ with Re using the slope linear regression through data points

\begin{tabular}{llllllll}
\hline Airfoil & RG15 & RG15-(00)-70-1 & RG15-(10)-70-1 & RG15-(20)-70-1 & RG15-(30)-70-1 & RG15-(40)-70-1 & RG15-(50)-70-1 \\
\hline (L/D) $\max$ & $1.536 \mathrm{E}-04$ & $1.552 \mathrm{E}-04$ & $1.548 \mathrm{E}-04$ & $1.563 \mathrm{E}-04$ & $1.594 \mathrm{E}-04$ & $1.605 \mathrm{E}-04$ & $1.610 \mathrm{E}-04$ \\
$\mathrm{C}_{\mathrm{L}_{\max }}$ & $4.536 \mathrm{E}-07$ & $4.853 \mathrm{E}-07$ & $4.910 \mathrm{E}-07$ & $4.796 \mathrm{E}-07$ & $3.532 \mathrm{E}-07$ & $4.437 \mathrm{E}-07$ & $3.634 \mathrm{E}-07$ \\
\hline
\end{tabular}


opposite behaviour was found for the angles of attack higher than $7^{\circ}$, where the airfoils with a larger thicknessto-chord ratio exhibit a smaller drag coefficient. A similar behaviour was also identified at $R e=300,000$; however, in the latter case, the drag dependence upon the thicknessto-chord ratio for the angles of attack below $7^{\circ}$ was much weaker.

\subsection{RANS simulations results}

RANS simulations were performed for each airfoil composing the proposed RG15 airfoil family at $R e=300,000$, considering a range of angles of attack from $-6^{\circ}$ to $12^{\circ}$. As previously noted, a new computational grid of similar resolution to Mesh 2 was generated for each airfoil and angle of attack. Thus, by including the original RG15 airfoil, 133 different computational grids were constructed during this study. Such a computational grid (for the flow simulation around RG15-(30)-70-1 airfoil at $\alpha=6^{\circ}$ ) is presented in Fig. 20.

\subsubsection{Aerodynamic coefficients}

Figure 21 illustrates the aerodynamic characteristics of the RG15 airfoil family at $R e=300,000$, as obtained by the RANS simulations. In accordance to the results of XFOIL analysis, no significant variation in the linear region of the lift coefficient has been observed with increasing thickness-to-chord ratio, as shown in Fig. 21a; a similar behavior in terms of drag coefficient was also found. Even though the drag coefficient seems to be proportional to the thickness-to-chord ratio, for the angles of attack ranging between $-5^{\circ}$ and $8^{\circ}$, a trend reversal was detected for the angles of attack higher than $8^{\circ}$, in which the airfoils with a larger thickness-to-chord ratio exhibit a smaller drag coefficient. This is probably attributed to the ability of the thicker airfoils of the RG15 family to maintain the flow attached at higher angles of attack (later and smoother stall). The quantification of the relationship between lift-to-drag ratio and angle of attack (Fig. 21c) is provided in Table 7.

However, as the preceding validation study already revealed, the drag levels estimated by the RANS solver are higher than those predicted by XFOIL solver; this conclusion can be easily drawn by observing both Fig. 21 b, d, as well as Table 8, which provides a comparison between the maximum lift-to-drag ratios resulted from XFOIL and RANS solvers, for each airfoil of the RG15 family. In particular, the RANS simulation resulted in maximum lift-to-drag ratios which are reduced by approximately $30 \%$, as compared to those of XFOIL anal$y$ yis, for each airfoil. Furthermore, significant differences can be detected on the prediction of the angle of attack in which the maximum lift-to-drag ratio is achieved.

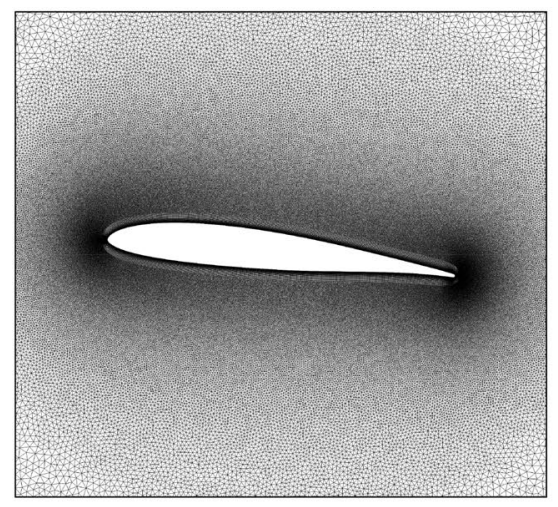

(a)

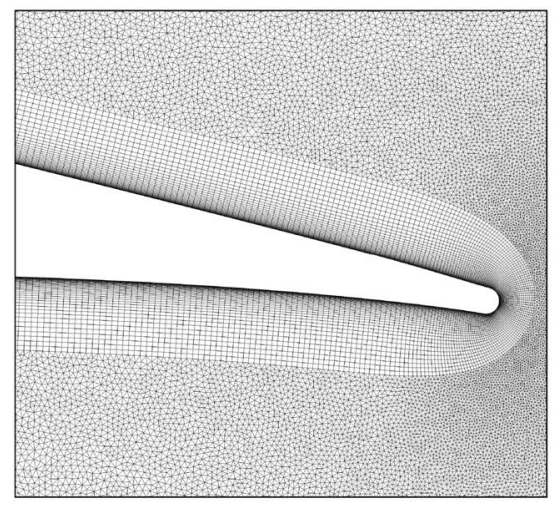

(b)

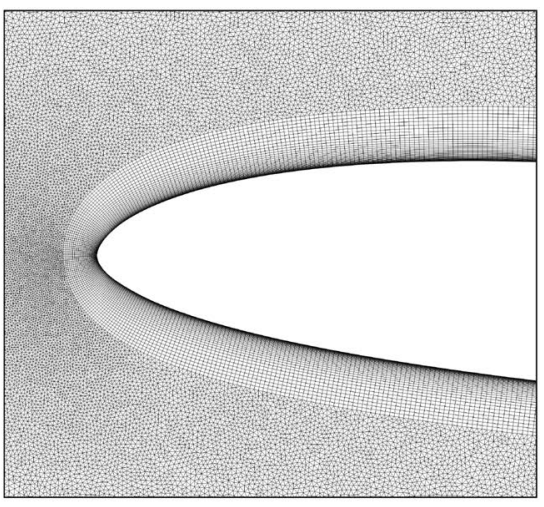

(c)

Fig. 20 The hybrid computational grid used for the flow field simulation of the RG15-(30)-70-1 airfoil at $\alpha=6^{\circ}$ 


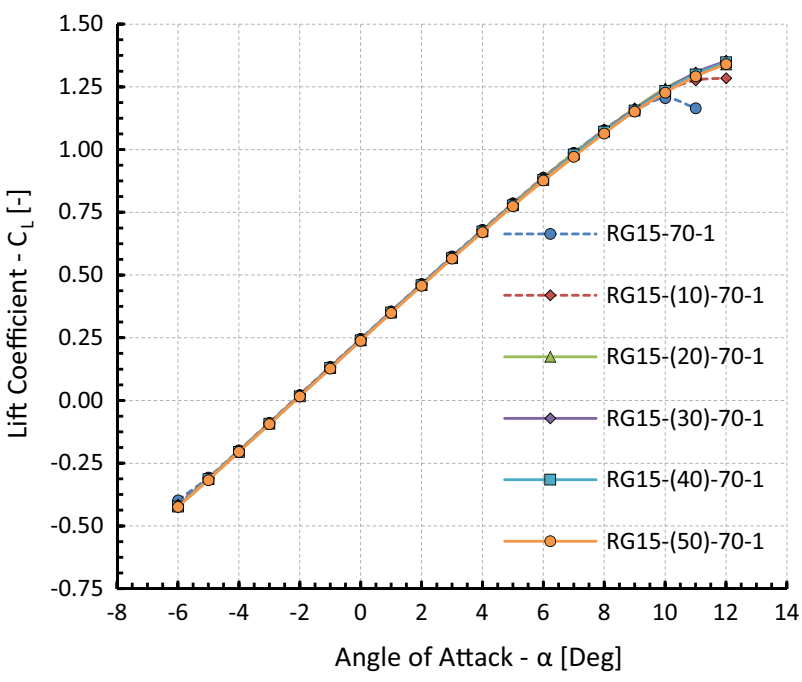

(a)

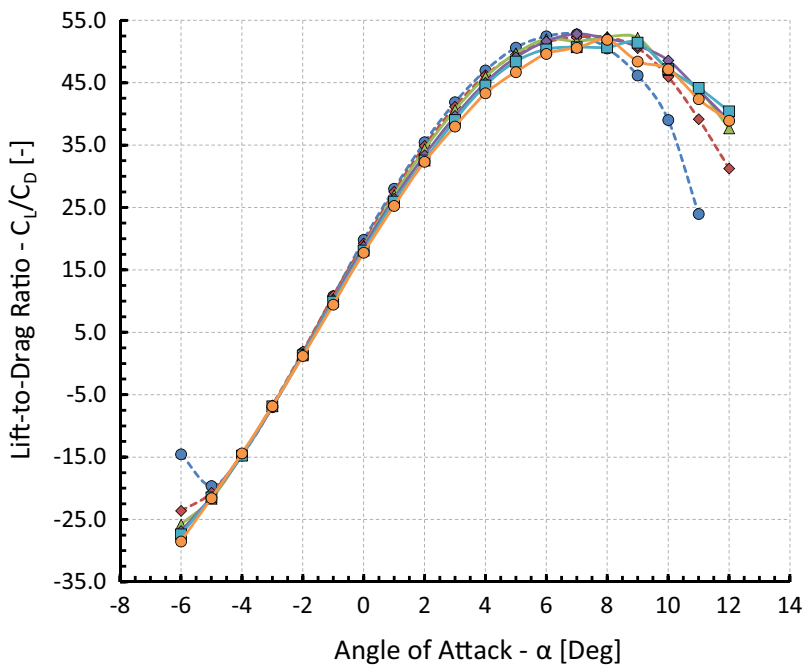

(c)

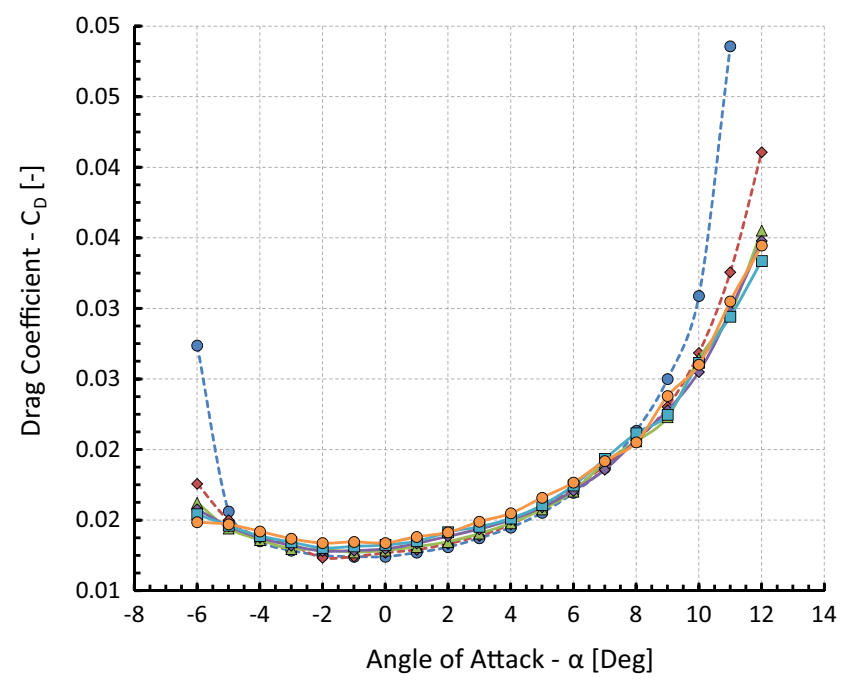

(b)

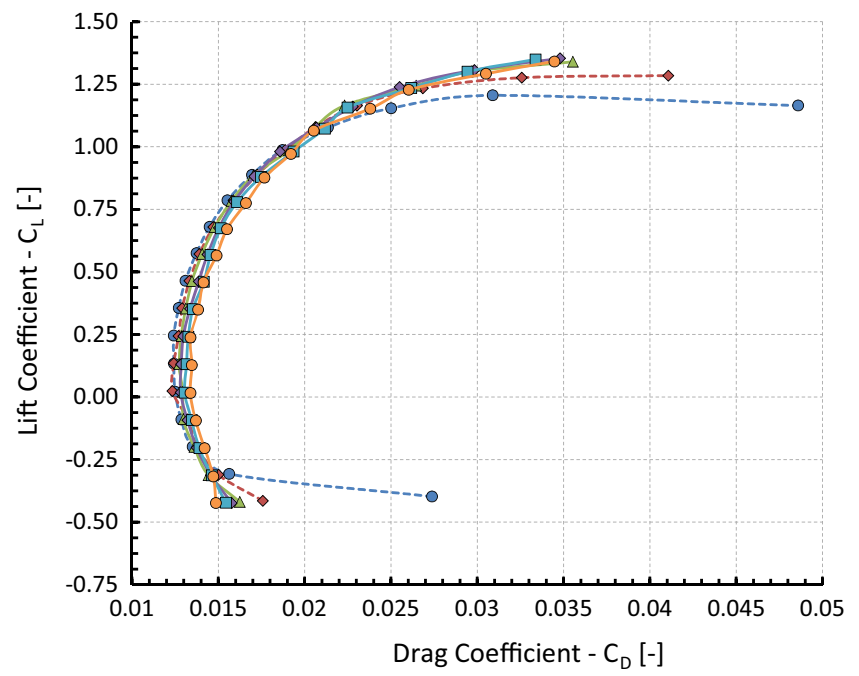

(d)

Fig. 21 Aerodynamic characteristics of the RG15 airfoil family at $R e=300,000$ (RANS analysis). a $C_{L}-\alpha . \mathbf{b} C_{D}-\alpha . \mathbf{c} C_{L} / C_{D}-\alpha . \mathbf{d} C_{L}-C_{D}$

Nevertheless, a fairly good agreement on the prediction of the percentage reduction of the maximum lift-to-drag ratio between the original and the thickened airfoils was found. For example, XFOIL predicted that the maximum lift-to-drag ratio of the RG15-(50)-70-1 was reduced by
$4.6 \%$, as compared to the original RG15; the estimation of the RANS solver on the corresponding reduction was equal to $3.2 \%$. A last remark on the RANS results concerns the high drag coefficient that was observed for the RG15-(00)-70-1 airfoil at $-6^{\circ}$ (Fig. 19b). According 
Table 7 Lift-to-drag ratio as a function of angle of attack at $R e=300,000$ (RANS analysis)

\begin{tabular}{|c|c|c|c|c|c|c|c|}
\hline \multicolumn{8}{|c|}{ 300,000 Reynolds number } \\
\hline AoA & RG15 & RG15-(00)-70-1 & RG15-(10)-70-1 & RG15-(20)-70-1 & RG15-(30)-70-1 & RG15-(40)-70-1 & RG15-(50)-70-1 \\
\hline$-6^{\circ}$ & -14.56 & -14.51 & -23.60 & -25.77 & -26.82 & -27.37 & -28.51 \\
\hline$-5^{\circ}$ & -19.55 & -19.62 & -20.69 & -21.66 & -21.42 & -21.42 & -21.56 \\
\hline$-4^{\circ}$ & -14.90 & -14.69 & -14.55 & -14.65 & -14.74 & -14.73 & -14.40 \\
\hline$-3^{\circ}$ & -7.23 & -6.95 & -6.67 & -6.77 & -6.98 & -6.83 & -6.84 \\
\hline$-2^{\circ}$ & 1.62 & 1.76 & 1.94 & 1.58 & 1.49 & 1.32 & 1.24 \\
\hline$-1^{\circ}$ & 10.84 & 10.80 & 10.89 & 10.36 & 10.20 & 9.95 & 9.47 \\
\hline $0^{\circ}$ & 19.97 & 19.83 & 19.26 & 18.90 & 18.76 & 18.14 & 17.80 \\
\hline $1^{\circ}$ & 28.48 & 28.04 & 27.53 & 27.01 & 26.42 & 25.96 & 25.27 \\
\hline $2^{\circ}$ & 36.15 & 35.50 & 34.89 & 34.38 & 33.39 & 32.56 & 32.37 \\
\hline $3^{\circ}$ & 42.60 & 41.89 & 41.19 & 40.66 & 39.71 & 39.05 & 38.00 \\
\hline $4^{\circ}$ & 47.74 & 46.99 & 46.22 & 45.94 & 45.01 & 44.60 & 43.32 \\
\hline $5^{\circ}$ & 51.40 & 50.66 & 49.54 & 49.72 & 49.12 & 48.43 & 46.73 \\
\hline $6^{\circ}$ & 53.42 & 52.46 & 51.54 & 52.01 & 51.65 & 50.37 & 49.65 \\
\hline $7^{\circ}$ & 53.65 & 52.80 & 52.30 & 51.65 & 52.85 & 50.72 & 50.62 \\
\hline $8^{\circ}$ & 51.18 & 50.51 & 52.31 & 52.34 & 52.06 & 50.68 & 51.89 \\
\hline $9^{\circ}$ & 46.27 & 46.17 & 50.57 & 52.23 & 50.93 & 51.47 & 48.43 \\
\hline $10^{\circ}$ & 39.49 & 39.04 & 45.97 & 47.05 & 48.60 & 47.20 & 47.18 \\
\hline $11^{\circ}$ & 27.68 & 23.98 & 39.19 & 43.87 & 43.83 & 44.20 & 42.38 \\
\hline $12^{\circ}$ & 16.32 & - & 31.29 & 37.71 & 38.92 & 40.42 & 38.93 \\
\hline
\end{tabular}

Table 8 Comparison between the results of XFOIL and RANS solvers, in terms of the maximum lift-to-drag ratio

\begin{tabular}{llllllll}
\hline 300,000 Reynolds number & & & & \\
\hline Airfoil & RG15 & RG15-(00)-70-1 & RG15-(10)-70-1 & RG15-(20)-70-1 & RG15-(30)-70-1 & RG15-(40)-70-1 & RG15-(50)-70-1 \\
\hline XFOIL (L/D) $\max$ & 78.76 & 78.65 & 77.80 & 77.31 & 76.56 & 75.84 & 75.12 \\
2D RANS (L/D) $\max$ & 53.64 & 52.80 & 52.31 & 52.34 & 52.85 & 51.47 & 51.89 \\
\hline
\end{tabular}

to the examination of the respective flow field, this is attributed to the presence of a large separation bubble on the lower surface of the particular airfoil, which encompasses a chordwise extend of approximately $9 \%$. It should be emphasized than no transition model or low-Re corrections for the turbulence model were used for RANS simulations in this study, which can partially explain the discrepancies between the XFOIL and RANS results.

\subsubsection{Comparison with XFOIL}

Further to the comparisons between the results of XFOIL and RANS solvers, Fig. 22 provides the distribution of the pressure coefficient along the RG15-(40)-70-1 airfoil, as obtained by the 2D RANS solver and XFOIL software, for various angles of attack between $-5^{\circ}$ and $10^{\circ}$. Although a good match is observed for the largest extend of the airfoil chord and both suction and pressure sides, 


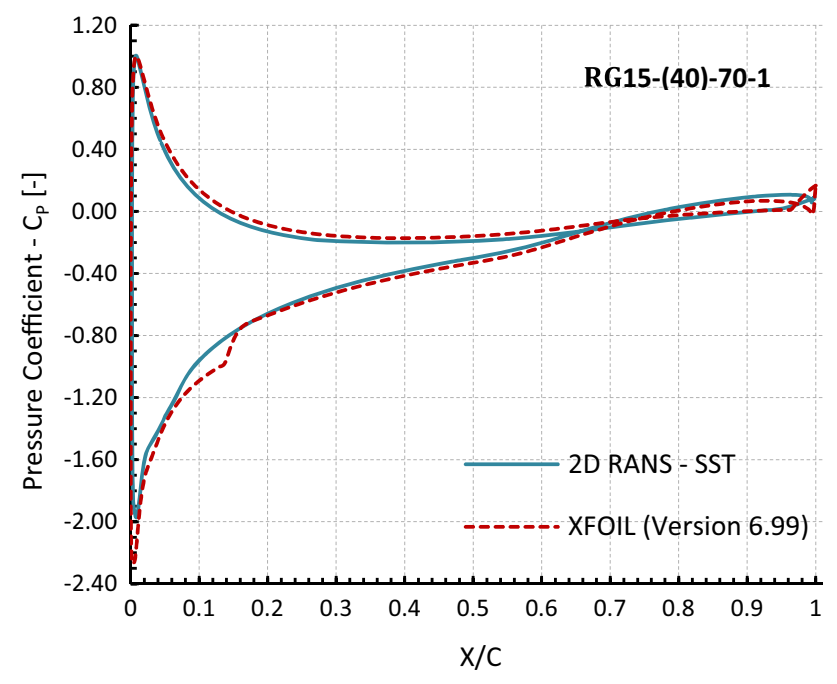

(a) $\alpha=-5^{o}$

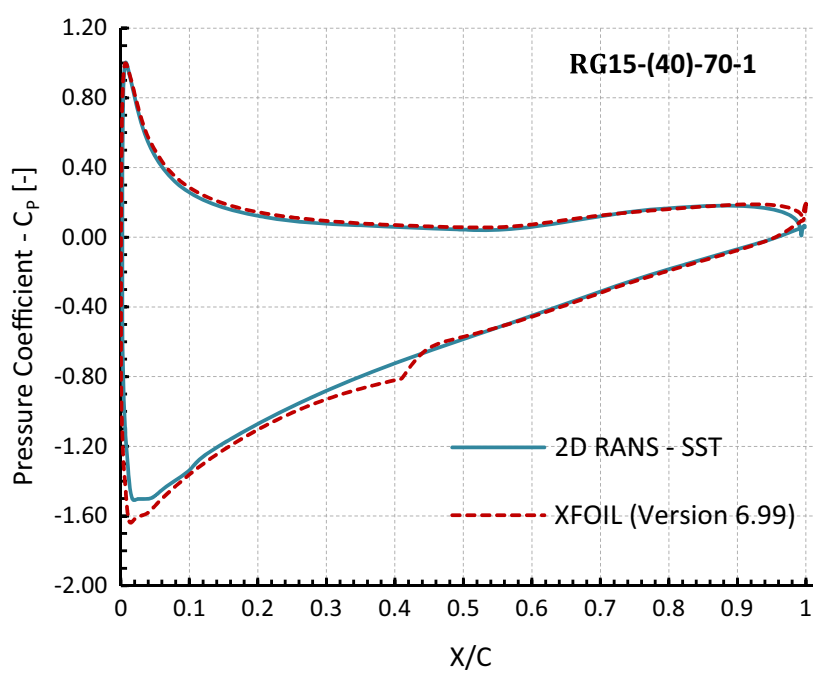

(c) $\alpha=5^{\circ}$

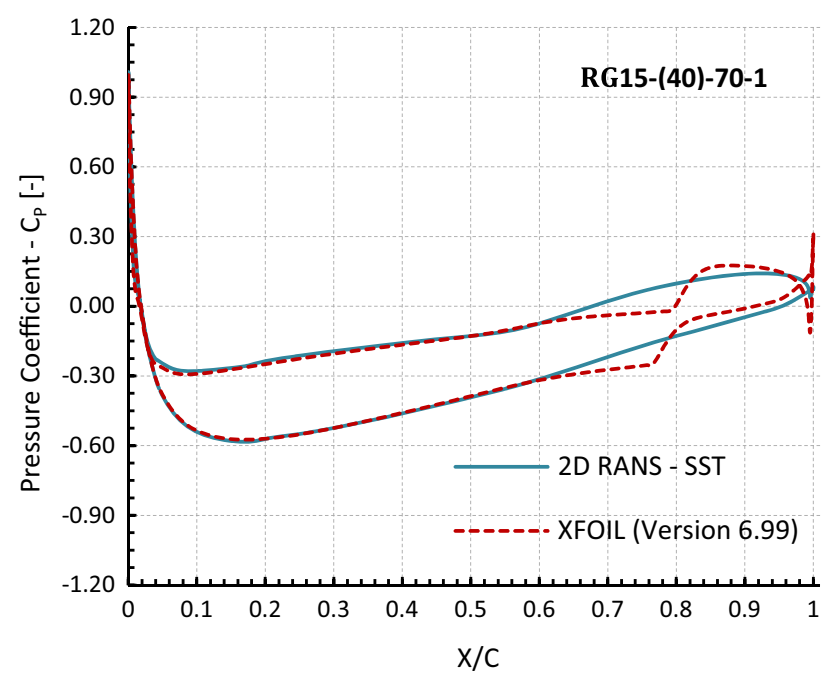

(b) $\alpha=0^{\circ}$

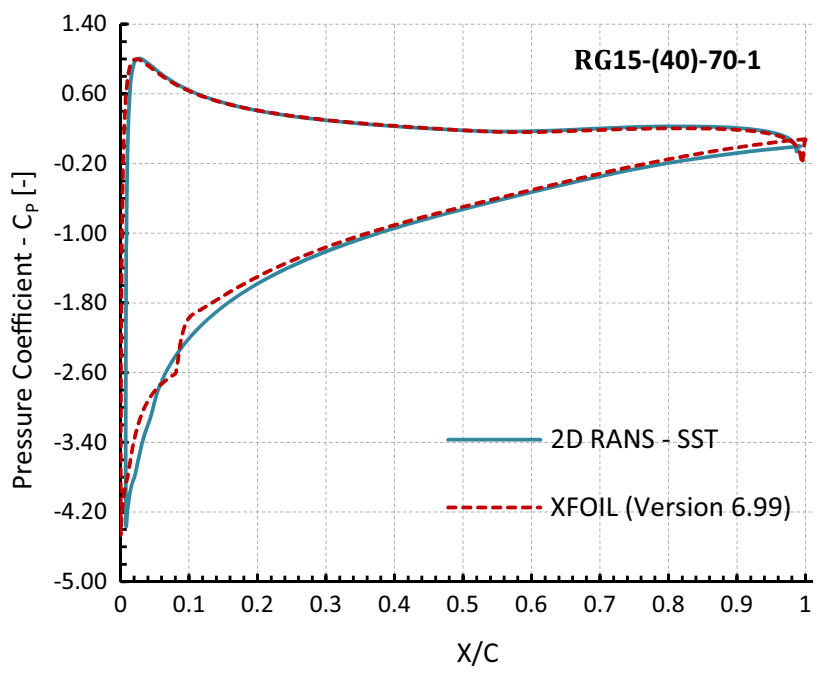

(d) $\alpha=10^{\circ}$

Fig. 22 Comparison of the pressure coefficient distributions obtained by XFOIL software and the 2D RANS solver for the RG15-(40)-70-1 airfoil at $\operatorname{Re}=300,000 . \mathbf{a} \alpha=-5^{\circ}$. b $\alpha=0^{\circ}$. c $\alpha=5^{\circ}$. d $\alpha=10^{\circ}$

significant discrepancies have been found around the points in which laminar to turbulent transition is realized. Obviously, this is attributed to the inability of the standard SST $k-\omega$ model to predict the particular phenomenon. The calculation of pressure coefficient was implemented through Eq. (8):
$C_{p}=\left(p-p_{\infty}\right) /\left(0.5 \rho V_{\infty}^{2}\right)$,

where $p_{\infty}$ is the free flow pressure.

Finally, a detailed comparison of the lift and drag curves for the entire RG15 airfoil family at $R e=300,000$ is provided in Figs. 23, 24, 25, 26, 27 28. Apparently, the 

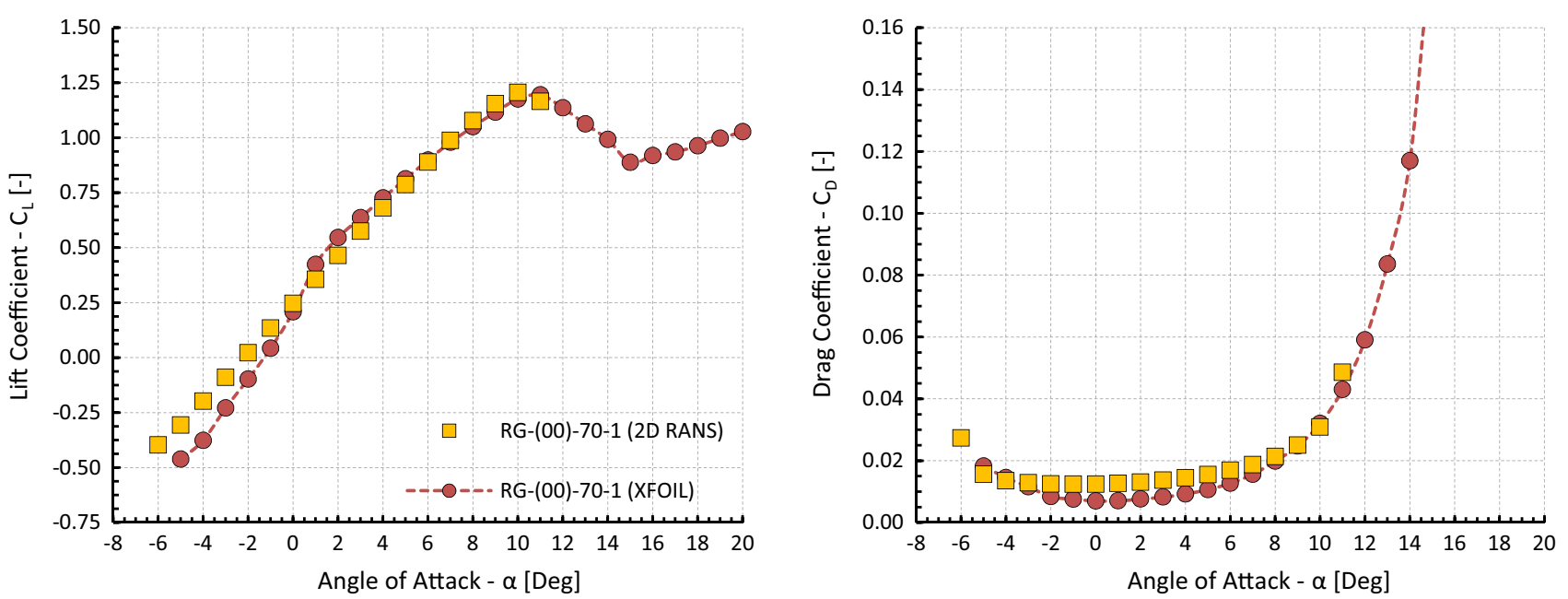

Fig. 23 Comparison between the lift and drag curves obtained by XFOIL and RANS solvers for the RG15-(00)-70-1 airfoil at Re = 300,000
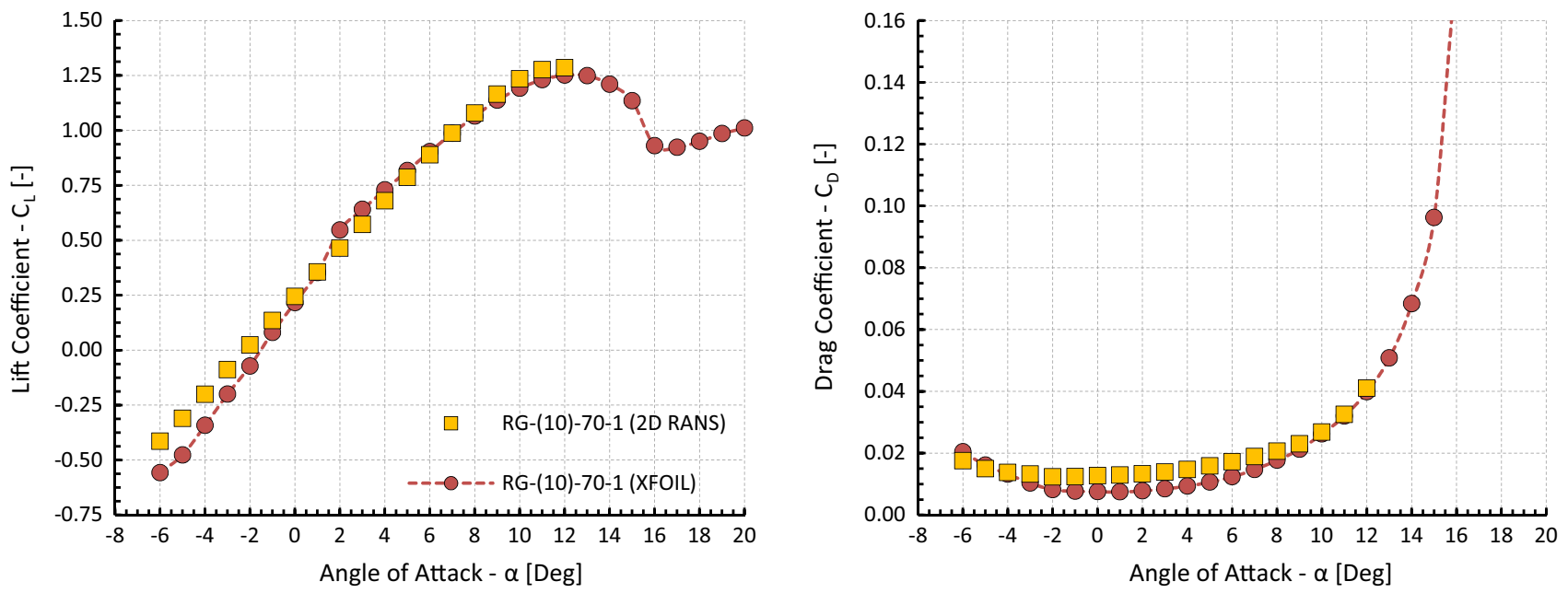

Fig. 24 Comparison between the lift and drag curves obtained by XFOIL and RANS solvers for the RG15-(10)-70-1 airfoil at Re = 300,000

drag levels predicted by the RANS solver are higher than those resulting from the XFOIL analysis for all the airfoils composing the RG15 family. On the other hand, a better match is observed for the lift coefficient curves, which tends to improve as the thickness-to-chord ratio of the airfoil increases.

\subsubsection{Flow field visualizations}

One of the most characteristic feature of the flow field around each one of the airfoils composing the RG15 family is the formation of a recirculation zone behind the rounded trailing edge, which is generally composed by two distinct 

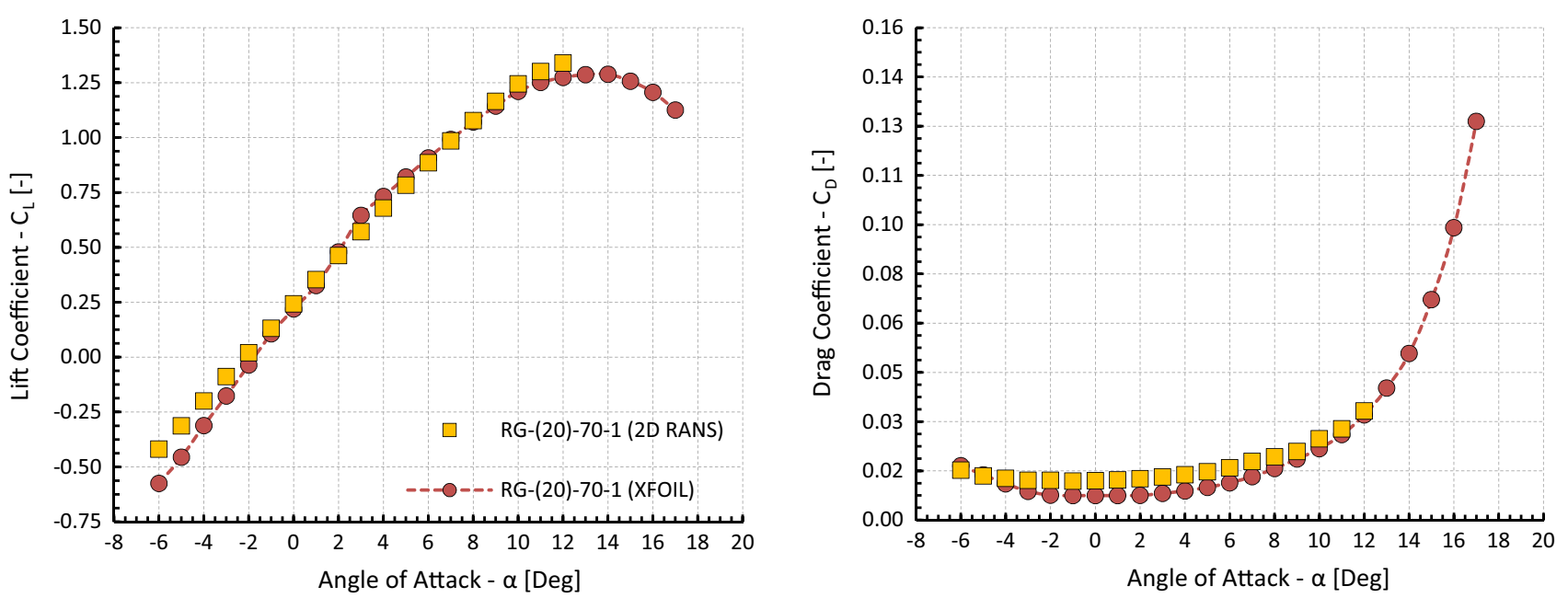

Fig. 25 Comparison between the lift and drag curves obtained by XFOIL and RANS solvers for the RG15-(20)-70-1 airfoil at Re = 300,000
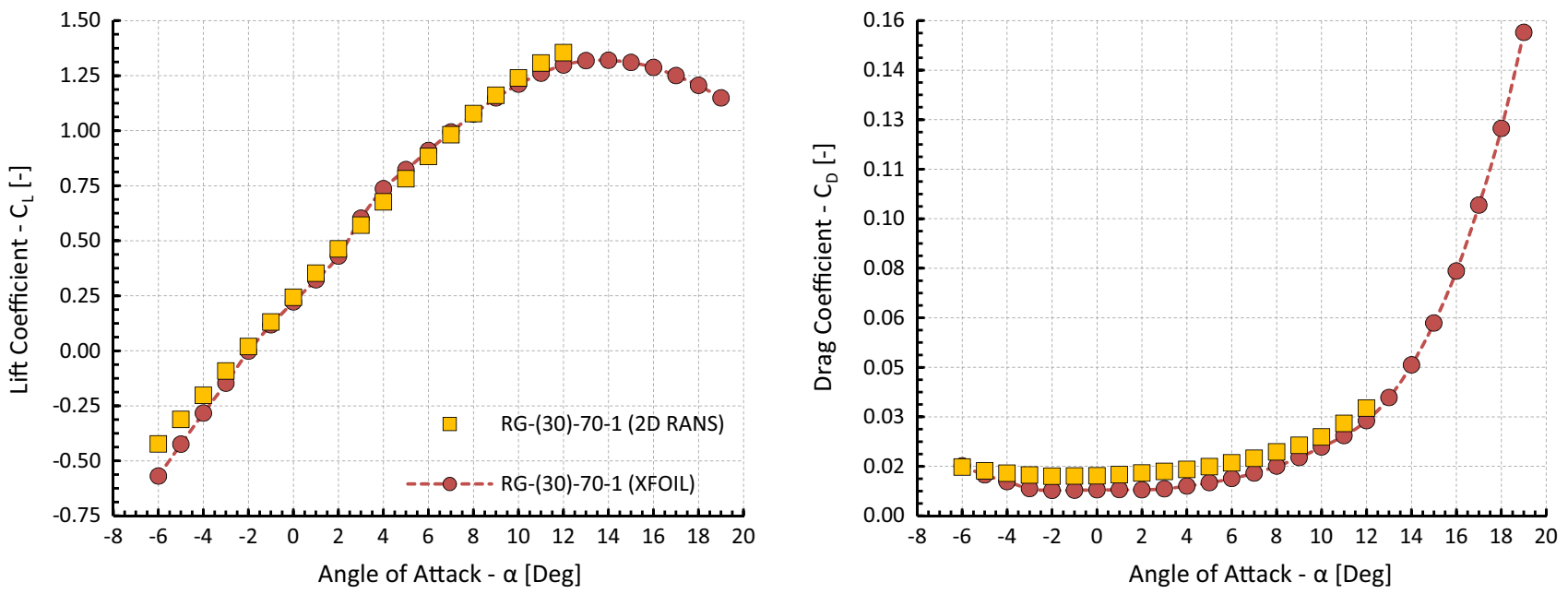

Fig. 26 Comparison between the lift and drag curves obtained by XFOIL and RANS solvers for the RG15-(30)-70-1 airfoil at Re = 300,000

vortex rings. Figure 29 illustrates the recirculation region behing the trailing edge of the proposed airfoils at $\alpha=0^{\circ}$ and $R e=300,000$. The vortex size is approximatelly equal to 1 percent of the chord length, while no variation in both size and behavior of the particular recirculation area has been observed by increasing the thickness-to-chord ratio of the airfoil.
Although the size of the recirculation zone seems not to be influenced by the thickness-to-chord ratio, it is highly dependent upon the angle of attack. Figure 30 presents the variation of the recirculation zone behind the trailing edge of the RG15-(30)-70-1 airfoil at $R e=300,000$ for several angles of attack between $-6^{\circ}$ and $12^{\circ}$. As it can be observed, the recirculation zone size decreases as the 

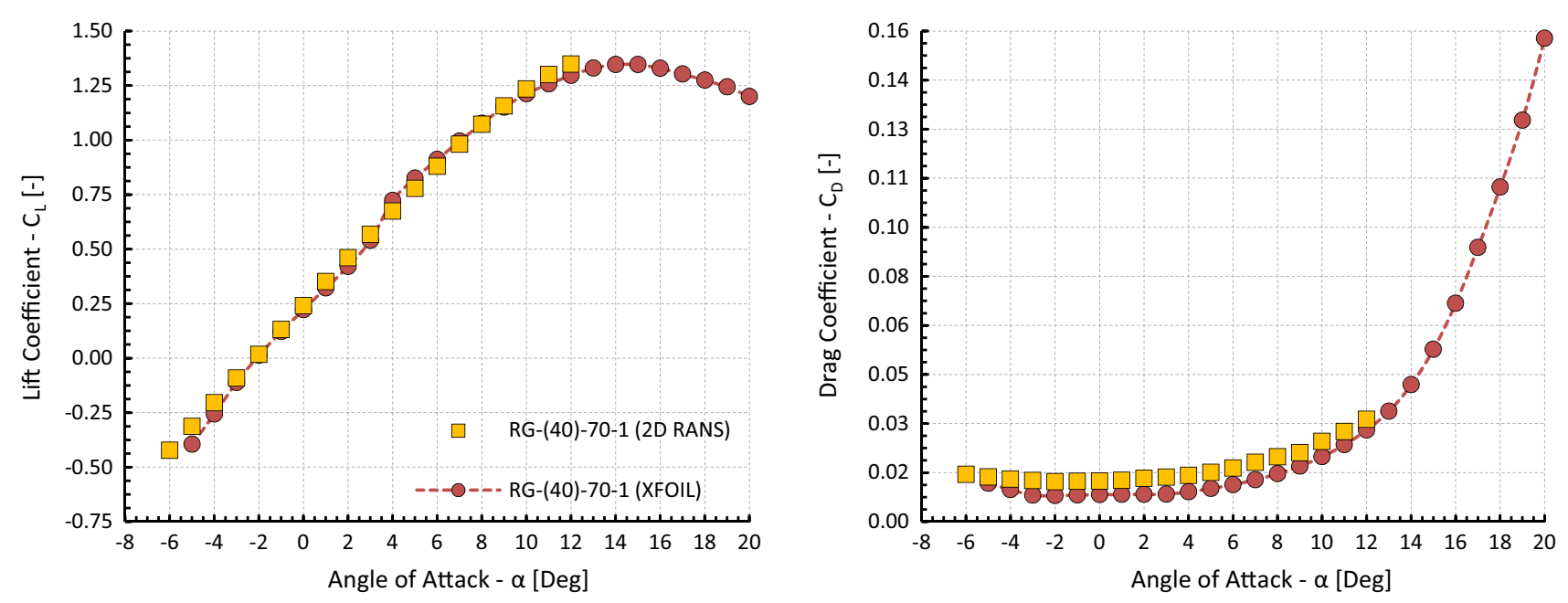

Fig. 27 Comparison between the lift and drag curves obtained by XFOIL and RANS solvers for the RG15-(40)-70-1 airfoil at Re = 300,000
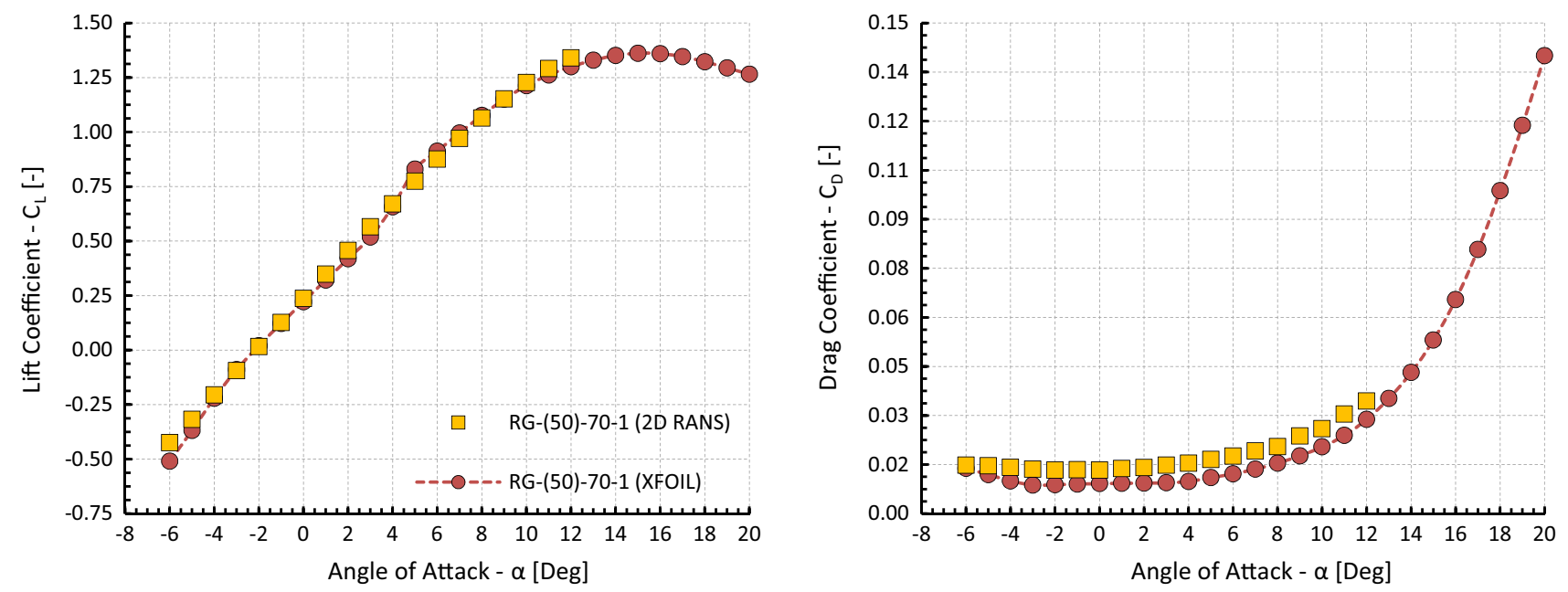

Fig. 28 Comparison between the lift and drag curves obtained by XFOIL and RANS solvers for the RG15-(50)-70-1 airfoil at Re = 300,000

angle of attack increases, until a trailing edge stall is established. Then, the recirculation region behind the trailing edge is substituted by a separated flow located on the suction side of the airfoil. According to the available numerical results, the first appearance of a trailing edge stall for the RG15-(30)-70-1 airfoil at $R e=300,000$ was made at an angle of attack between $10^{\circ}$ and $11^{\circ}$. A similar behavior in terms of the recirculation zone behind the rounded trailing edge was found during the analysis of the numerical results for the rest airfoils of the RG15 family. However, in the cases of RG15-(40)-70-1 and RG15-(50)-70-1 airfoils, the first appearance of a trailing edge stall was observed at an 


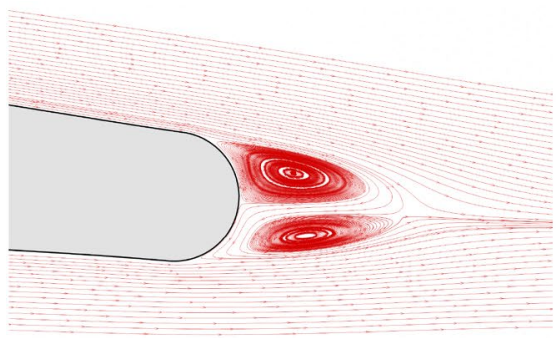

(a) RG15-(00)-70-1

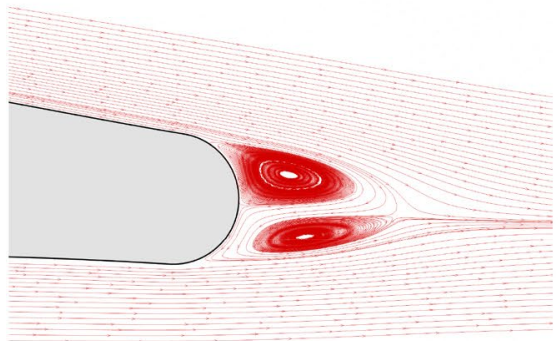

(d) RG15-(30)-70-1

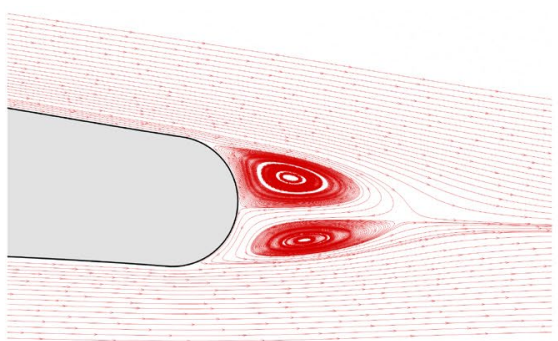

(b) RG15-(10)-70-1

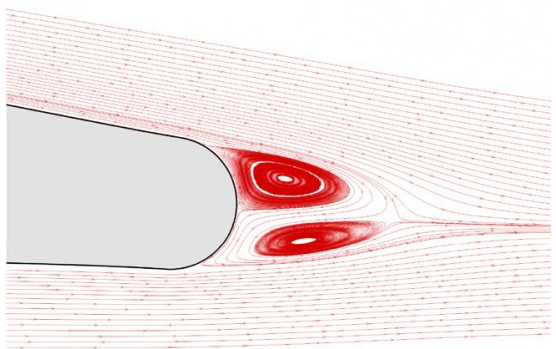

(e) RG15-(40)-70-1

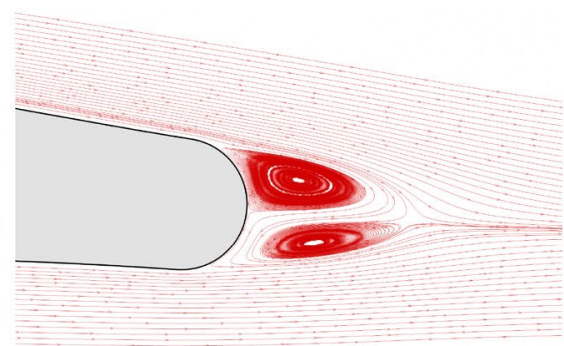

(c) RG15-(20)-70-1

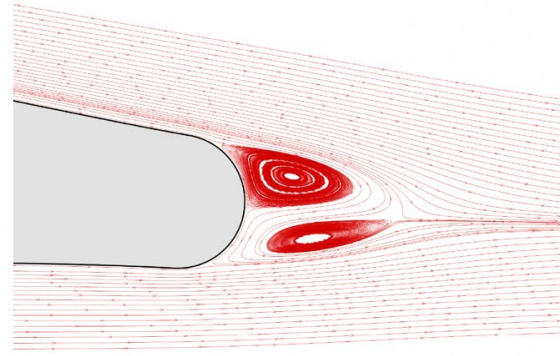

(f) RG15-(50)-70-1

Fig. 29 Recirculation area behind the rounded trailing edges of the proposed airfoils at $\alpha=0^{\circ}$ and $\operatorname{Re}=300,000$

angle of attack between $9^{\circ}$ and $10^{\circ}$ (that is slightly smaller than the corresponding angle of attack for the rest of the RG15 airfoils).

Apart from the improvement of the structural characteristics, the thickening of the RG15 airfoil seems to also have a beneficial impact on the appearance of separation bubbles. Especially, as the thickness-to-chord ratio increases the first appearance of a separation bubble moves to higher angles of attack. Figure 31 illustrates the velocity streamlines around the leading edge of the airfoils composing the proposed RG15 family at $\alpha=12^{\circ}$. As it is observed, an open separation area has been formed on the suction side of RG15-(00)-70-1. However, by increasing the thickness-to-chord ratio, the open separation area is substituted by a short separation bubble (Fig. 31b) covering a chordwise extend of approximately $1.6 \%$. Further increase of the airfoil thickness results in the reduction of the bubble's size, accompanied by its movement away from the leading edge. Eventually, no separation bubble was detected on the upper surface of RG-(50)-70-1. Finally, Figs. 32 and 33 illustrate the pressure and axial velocity contours for each one of the airfoils composing the RG15 family at the angle of attack in which the maximum lift-todrag ratio was detected.

\section{Conclusions}

In this study, a low-Reynolds airfoils family (consisted of six airfoils) suitable for the entire blade span of small horizontal-axis wind turbines has been designed, aiming to reduce the effects related to laminar separation, increase the structural integrity of the blade, enhance the startup behavior of the wind turbine and meet the current blade manufacturing limitations. Initially, 5 thickened airfoils were constructed based on the RG15 airfoil. According 


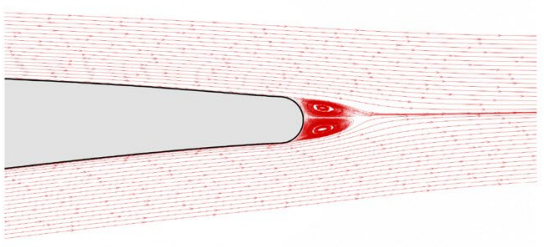

(a) $\alpha=-6^{o}$

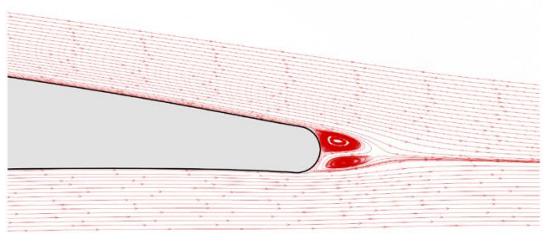

(d) $\alpha=0^{o}$

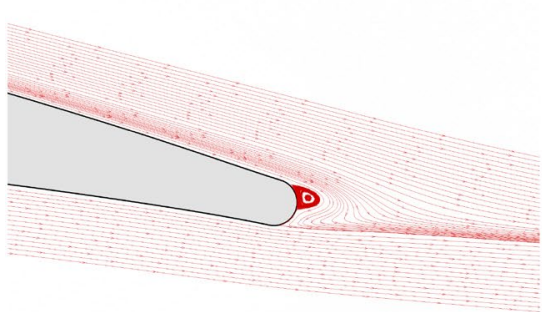

(g) $\alpha=8^{\circ}$

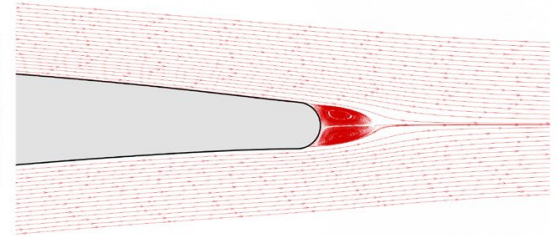

(b) $\alpha=-4^{o}$

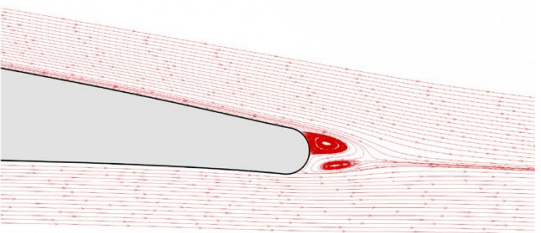

(e) $\alpha=2^{o}$

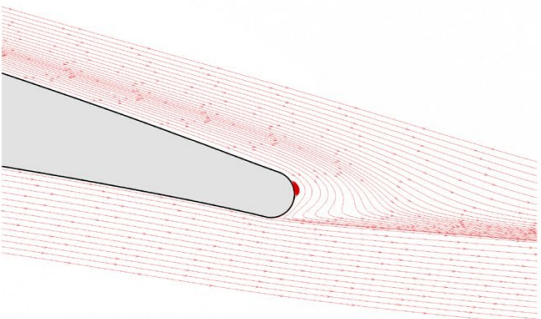

(h) $\alpha=1^{\circ}$

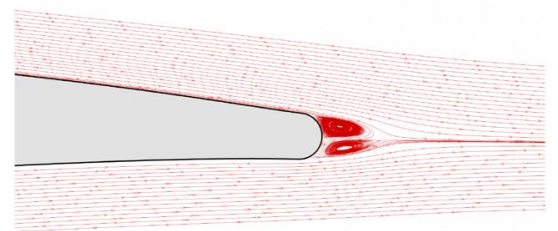

(c) $\alpha=-2^{o}$

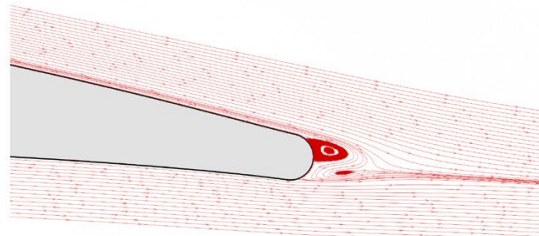

(f) $\alpha=4^{o}$

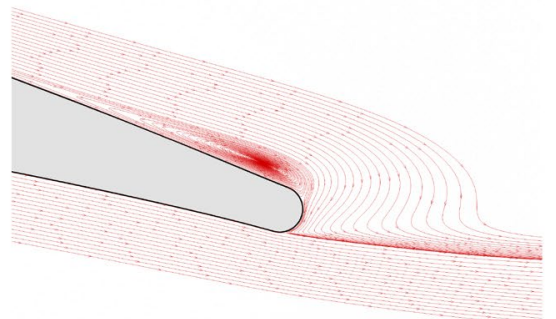

(i) $\alpha=12^{o}$

Fig. 30 Variation of the recirculation zone behind the trailing edge of the RG15-(30)-70-1 airfoil with the angle of attack at $\operatorname{Re}=300,000$

to the followed methodology, the thickened airfoils were designed in such a way that they have the same mean camber line (MCL), as compared to the one of the original RG15 airfoil (so as to retain its desirable aerodynamic characteristics), but an increased thickness-to-chord ratio distribution by $50 \%, 40 \%, 30 \%, 20 \%$ and $10 \%$ respectively. Then, another custom script was applied to the original and the thickened RG15 airfoils, for the generation of a rounded trailing edge without truncating the airfoil, through the proper modification (local thickening) of the provided airfoil geometries. The final airfoil family resulted through the application of a parabolic thickness distribution to the thickened airfoils, at their trailing edge region, setting the value for the blending distance equal to $70 \%$ and the trailing edge radius equal to $0.5 \%$ of the chord length respectively. According to the aerodynamic evaluations performed with XFOIL code at various low Reynolds numbers, the dependence of the blending distance on the 


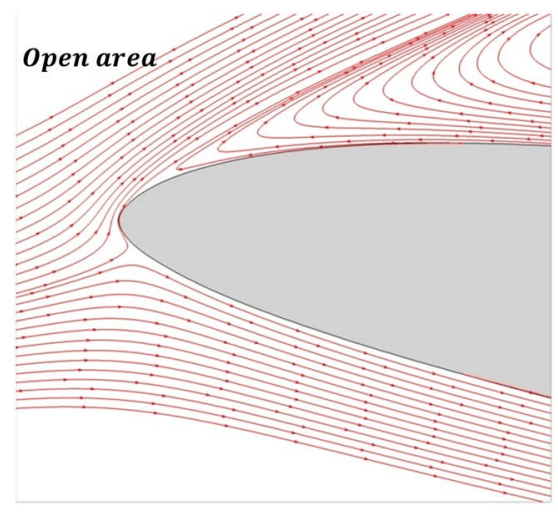

(a) RG15-(00)-70-1

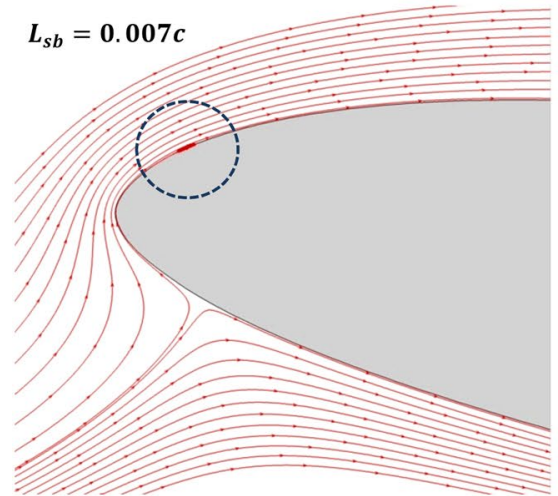

(d) RG15-(30)-70-1

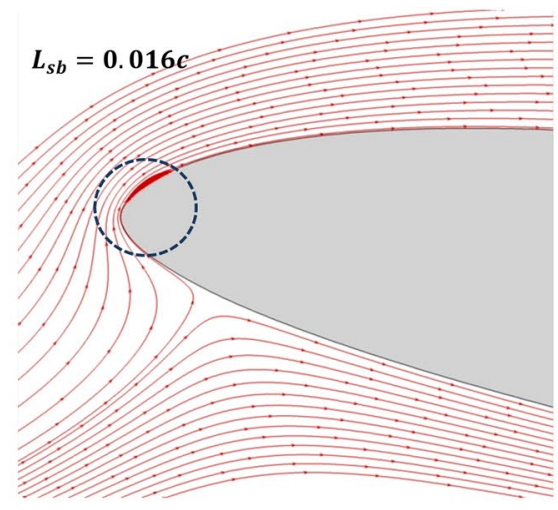

(b) RG15-(10)-70-1

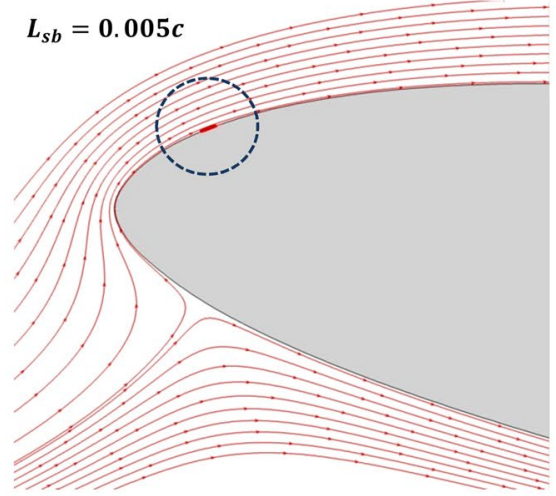

(e) RG15-(40)-70-1

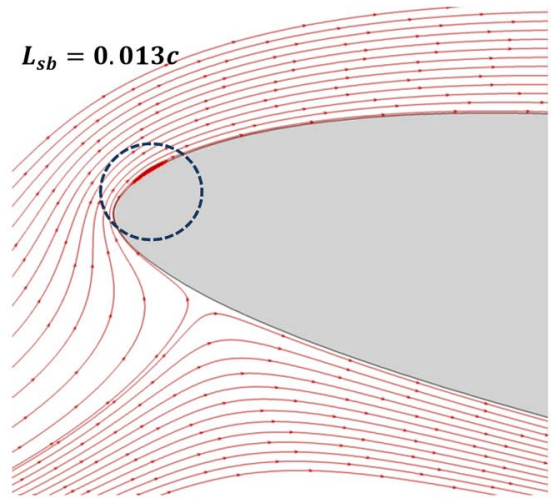

(c) RG15-(20)-70-1

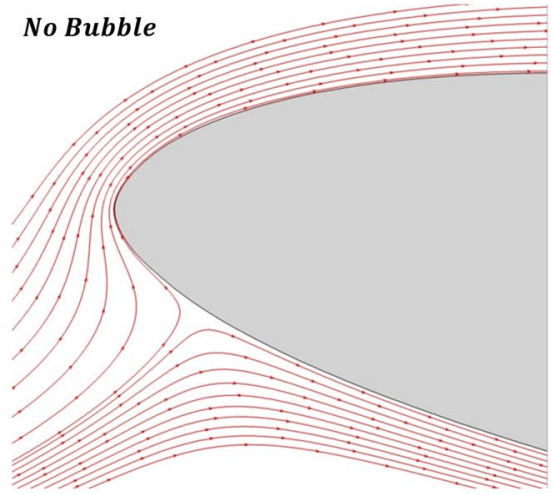

(f) RG15-(50)-70-1

Fig. 31 The variation of separation bubble with thickness-to-chord ratio at $\alpha=12^{\circ}$

lift and drag coefficients was found practically zero; the same conclusion was drawn for the dependence of the aerodynamic coefficients on the rounded trailing edge with a radius of $0.5 \%$ of the chord.

The aerodynamic performance of the entire RG15 airfoil family was initially evaluated by using XFOIL software for various low Reynolds numbers ranging from $R e=60,000$ to $R e=300,000$. The results of the XFOIL analysis revealed that the increase of the thickness-to-chord ratio leads to the reduction in the maximum lift-to-drag ratio for each one of the considered Reynolds numbers. However, as the Reynolds number increases the particular percentage reduction decreases. Apparently, the maximum reduction in the maximum lift-to-drag ratio, as compared to the one of the original RG15 airfoil, was found for the lowest $R e$ examined $(60,000)$ and the RG15-(50)-70-1 airfoil (the thicker airfoil of the RG15 family); this percentage reduction was equal to $12.68 \%$. The corresponding percentage at $R e=300,000$ was equal to $4.6 \%$. Nevertheless, even the largest reduction of the maximum lift-to-drag ratio seems 


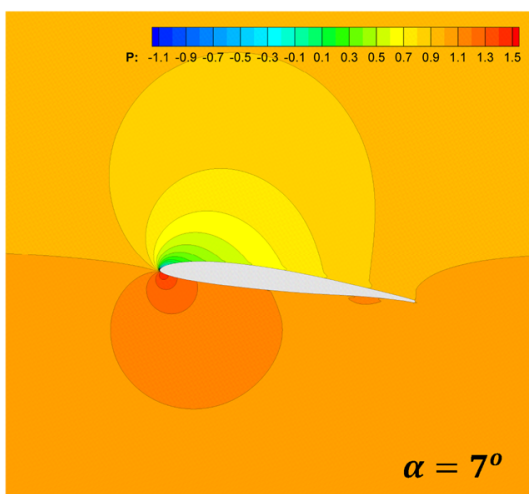

(a) RG15-(00)-70-1

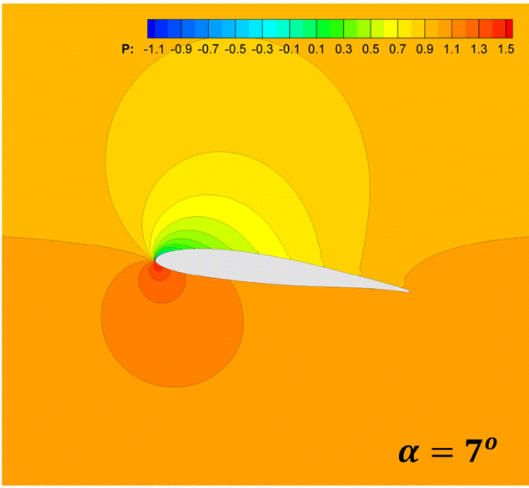

(d) RG15-(30)-70-1

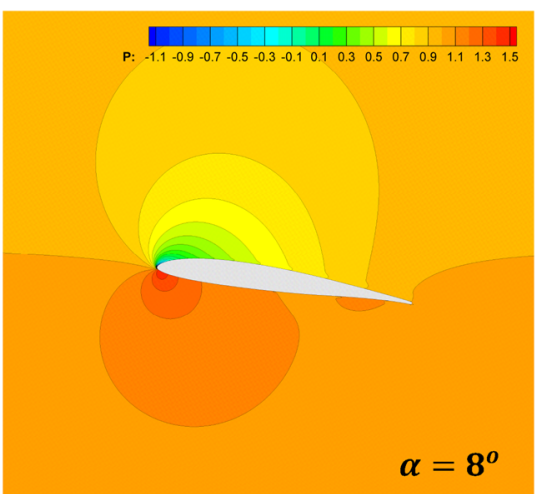

(b) RG15-(10)-70-1

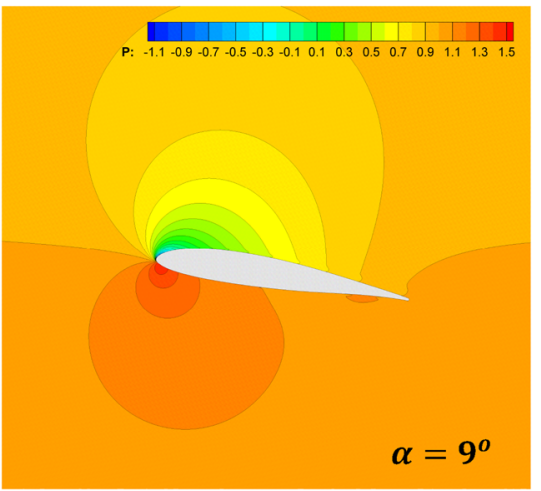

(e) RG15-(40)-70-1

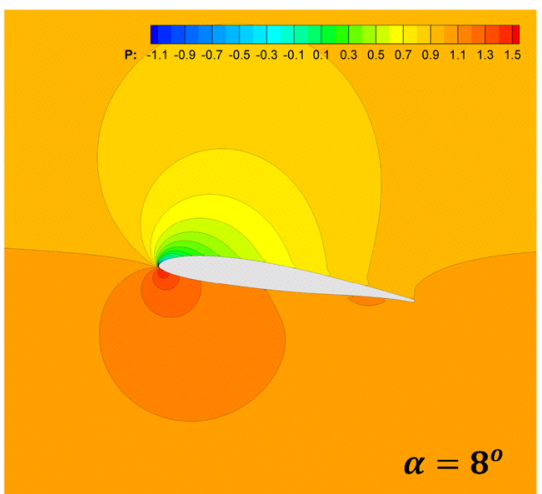

(c) RG15-(20)-70-1

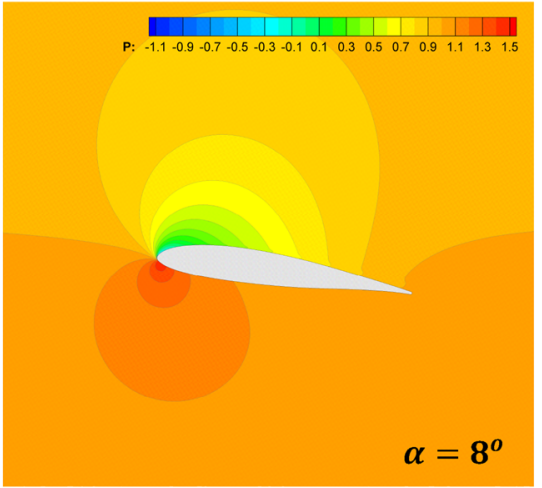

(f) RG15-(50)-70-1

Fig. 32 The pressure contours around each one of the airfoils composing the RG15 family at the angle of attack leading to the maximum lift-to-drag ratio $(R e=300,000)$

minor given that this airfoil has a maximum thickness-tochord ratio that is $50 \%$ higher than the maximum thickness-to-chord ratio of the baseline RG15 airfoil, accompanied by cross-sectional area that has been increased by approximately $52 \%$. On the other hand, a growth of the maximum lift coefficient for each $R e$ was found by increasing the thickness-to-chord ratio.

Moreover, the performance of the RG15 airfoil family was further examined by employing an in-house 2D RANS solver, using the standard two-equation SST $k-\omega$ turbulence model. The RANS simulations were performed at $R e=300,000$. Although the results of the RANS simulation were generally in accordance with those of XFOIL, a notable over-estimation of the drag coefficient was detected, leading to the under-estimation of the lift-to-drag ratio. Such an outcome clearly indicates that a low Reynolds number correction model is essential, in order to increase the accuracy of the numerical results. Finally, the behavior of the recirculation area behind the rounded trailing edge for different angles of attack was examined, while the thickening of the airfoils was found to have a beneficial impact on the appearance of separation bubbles. 


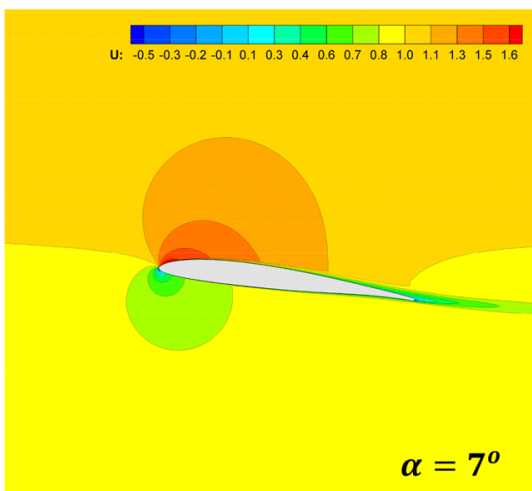

(a) RG15-(00)-70-1

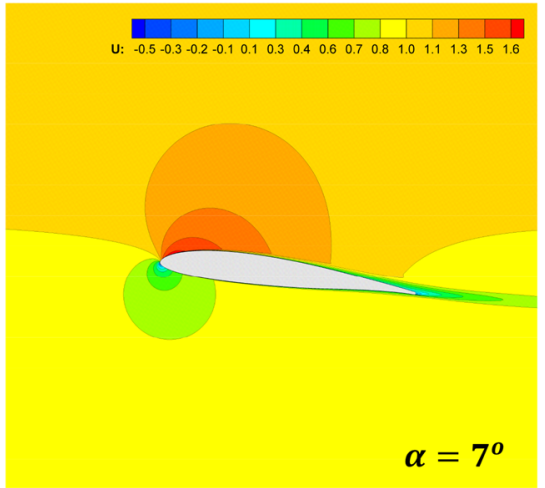

(d) RG15-(30)-70-1

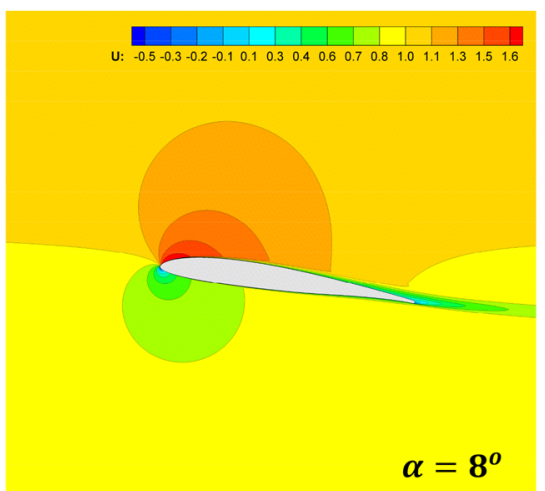

(b) RG15-(10)-70-1

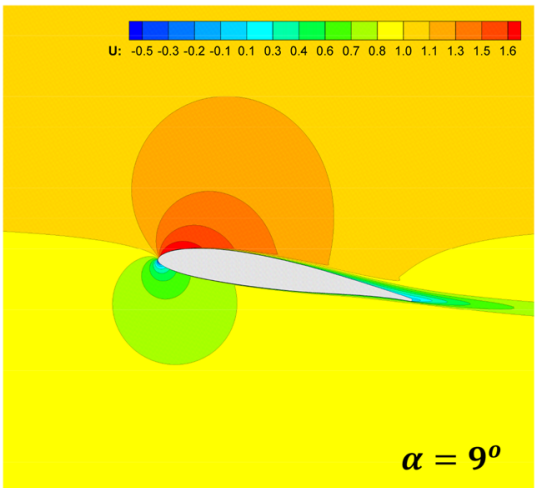

(e) RG15-(40)-70-1

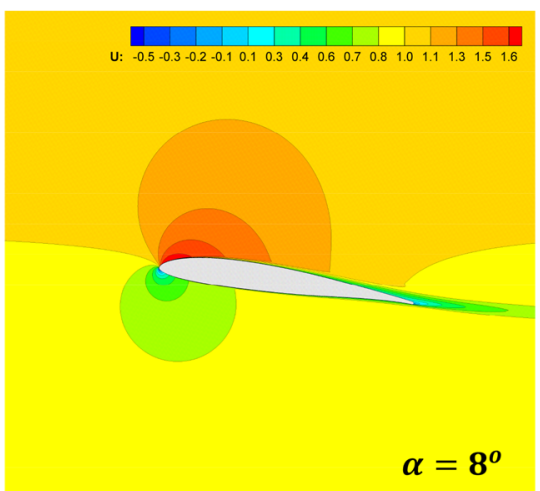

(c) RG15-(20)-70-1

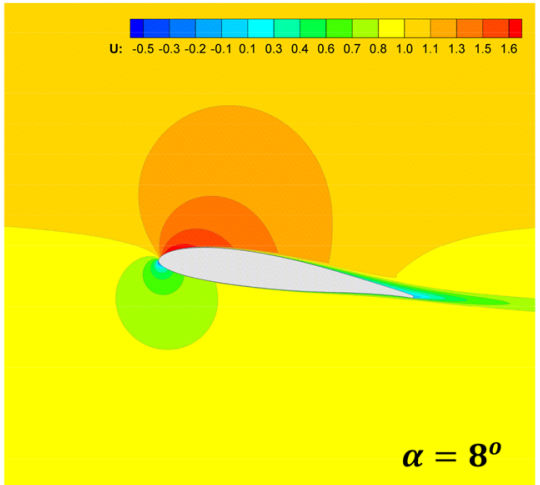

(f) RG15-(50)-70-1

Fig. 33 The axial velocity contours around each one of the airfoils composing the RG15 family at the angle of attack leading to the maximum lift-to-drag ratio $(R e=300,000)$

\section{Compliance with ethical standards}

Conflict of interest On behalf of all authors, the corresponding author states that there is no conflict of interest.

\section{References}

1. Singh RK, Ahmed MR, Zullah MA, Lee YH (2012) Design of a low Reynolds number airfoil for small horizontal axis wind turbines. Renew Energy 42:66-76. https://doi.org/10.1016/j.renen e.2011.09.014

2. Yang H, Chen J, Pang X, Chen G (2019) A new aero-structural optimization method for wind turbine blades used in low wind speed areas. Compos Struct 207:446-459. https://doi. org/10.1016/j.compstruct.2018.09.050

3. IEC 61400-2:2013 Wind turbines-part 2: design requirements for small wind turbines. https://webstore.iec.ch/publicatio $\mathrm{n} / 5433$

4. Shah H, Bhattarai N, Mathew S, Lim CM (2012) Low Reynolds number airfoil for small horizontal axis wind turbine blades. In: Sustainable future energy 2012 and 10th SEE Forum, 21-23 November 2012, Brunei, Darussalam. https://doi.org/10.13140 /2.1.2633.4081

5. Giguère P, Selig MS (1997) Low Reynolds number airfoils for small horizontal axis wind turbines. Wind Eng 21:367-380
6. Alam M, Sandham ND (2000) Direct numerical simulation of 'short' laminar separation bubbles with turbulent reattachment. J Fluid Mech 410:1-28. https://doi.org/10.1017/S0022 112099008976

7. Mulleners K, Henning A, Raffel M (2008) Investigations of a trailing edge stall on 2D airfoils. In: 14th international symposium on applications of laser techniques to fluid mechanics, 7-10 July 2008, Lisbon, Portugal. http://infoscience.epfl.ch/record/21823 5

8. Swift K (2009) An experimental analysis of the laminar separation bubble at low Reynolds numbers. Master Thesis, University of Tennessee

9. Tani I (1961) Critical survey of published theories on the mechanism of leading-edge stall. Aeronautical Research Institute, University of Tokyo, Report No. 367

10. Choudhry A, Arjomandi M, Kelso R (2015) A study of long separation bubble on thick airfoils and its consequent effects. Int J Heat Fluid Flow 52:84-96. https://doi.org/10.1016/j.ijheatflui dflow.2014.12.001

11. Hansen KL, Kelso RM, Choudhry A, Arjomandi M (2014) Laminar separation bubble effect on the lift curve slope of an airfoil. In: 19th Australasian Fluid Mechanics Conference, 8-11 December 2014, Melbourne, Australia

12. Lyon C, Selig M, Broeren A (1997) Boundary layer trips on airfoils at low Reynolds numbers. In: 35th Aerospace Sciences Meeting and Exhibit, AIAA, 6-7 January 1997, Reno, Nevada, USA. https ://doi.org/10.2514/6.1997-511 
13. Somers DM (2005) S822 and S823 airfoils: October 1992-December 1993. National Renewable Energy Laboratory (NREL). Report No: NREL/SR-500-36342. https://doi.org/10.2172/15011666

14. Broeren AP, Giguere P, Selig MS, Guglielmo JJ (1995) Summary of low-speed airfoil data, vol 1. SoarTech Publications, Virginia Beach

15. Giguere P, Selig MS (1998) New airfoils for small horizontal axis wind turbines. J Sol Energy Eng 120:108-114. https://doi. org/10.1115/1.2888052

16. Selig MS, McGranahan BD (2004) Wind tunnel aerodynamic tests of six airfoils for use on small wind turbines. J Sol Energy Eng 126:986-1001. https://doi.org/10.1115/1.1793208

17. Ram KR, Lal S, Rafiuddin Ahmed M (2013) Low Reynolds number airfoil optimization for wind turbine applications using genetic algorithm. J Renew Sustain Energy 5:052007. https:// doi.org/10.1063/1.4822037

18. Henriques JCC, Marques da Silva F, Estanqueiro Al, Gato LMC (2009) Design of a new urban wind turbine airfoil using a pressure-load inverse method. Renew Energy 34:2728-2734. https ://doi.org/10.1016/j.renene.2009.05.011

19. Islam M, Amin MR, Ting DS-K, Fartaj A (2009) Selection of airfoils for straight-bladed vertical axis wind turbines based on desirable aerodynamic characteristics. In: ASME 2008 International Mechanical Engineering Congress and Exposition, 31 October-6 November 2018, Boston, Massachusetts, USA. https:// doi.org/10.1115/IMECE2008-66027

20. Marnett M, Yang S, Schroder W (2010) Lightweight airfoil design for a series of small vertical axis wind turbines. In: European Wind Energy Conference and Exhibition, 20-23 April 2010, Warsaw, Poland

21. Shen X, Avital E, Paul G, Rezaienia MA, Wen P, Korakianitis T (2016) Experimental study of surface curvature effects on aerodynamic performance of a low Reynolds number airfoil for use in small wind turbines. J Renew Sustain Energy 8:053303. https ://doi.org/10.1063/1.4963236

22. Sathyajith M, Philip GS (2011) Advances in wind energy conversion technology. Springer, Berlin. https://doi.org/10.1007/9783-540-88258-9

23. Wright AK, Wood DH (2004) The starting and low wind speed behaviour of a small horizontal axis wind turbine. J Wind Eng Ind Aerodyn 92:1265-1279. https://doi.org/10.1016/j.jweia .2004 .08 .003

24. Stack J, Lindsey WF (1938) Tests of N-85, N-86 and N-87 airfoil sections in the 11-inch high speed wind tunnel. National Advisory Committee for Aeronautics, Technical Note No. 665, Washington, USA. https://digital.library.unt.edu/ark:/67531/ metadc54455

25. Herrig LJ, Emery JC, Erwin JR (1951) Effect of section thickness and trailing-edge radius on the performance of NACA 65 -series compressor blades in cascade at low speeds. National Advisory Committee for Aeronautics, Research Memorandum L51J16, Langley Aeronautical Laboratory Langley Field, Virginia, USA. https://digital.library.unt.edu/ark:/67531 /metadc59078

26. Marten D (2015) QBlade Guidelines v0.9. Technical University of Berlin, Germany. http://www.q-blade.org
27. Drela M (1989) XFOIL: an analysis and design system for low Reynolds number airfoils. In: Mueller TJ (ed) Low Reynolds number aerodynamics. Lecture Notes in Engineering. Springer, Berlin, pp 1-12

28. Leloudas SN, Lygidakis GN, Strofylas GA, Nikolos IK (2018) Aerodynamic shape optimization of diffuser augmented wind turbine shrouds using asynchronous differential evolution. In: ASME 2018 international mechanical engineering congress and exposition, 9-15 November 2018, Pittsburgh, Pennsylvania, USA. https://doi.org/10.1115/IMECE2018-86820

29. Coder JG, Maughmer MD (2014) Comparisons of theoretical methods for predicting airfoil aerodynamic characteristics. J Aircr 51:183-191. https://doi.org/10.2514/1.C032232

30. Drela M, Giles MB (1987) Viscous-inviscid analysis of transonic and low Reynolds number airfoils. AIAA J 25:1347-1355. https ://doi.org/10.2514/3.9789

31. van Ingen $J L$ (2008) The $\mathrm{e}^{\mathrm{N}}$ method for transition prediction. Historical review of work at TU Delft. In: 38th Fluid Dynamics Conference and Exhibit, 23-26 June 2008, Seattle, Washington, USA. https://doi.org/10.2514/6.2008-3830

32. Morgado J, Vizinho R, Silvestre MAR, Páscoa JC (2016) XFOIL vs CFD performance predictions for high lift low Reynolds number airfoils. Aerosp Sci Technol 52:207-214. https://doi. org/10.1016/j.ast.2016.02.031

33. Menter FR (1994) Two-equation eddy-viscosity turbulence models for engineering applications. AIAA J 32:1598-1605. https:// doi.org/10.2514/3.12149

34. Menter FR, Carregal Ferreira J, Esch T, Konno B (2003) The SST turbulence model with improved wall treatment for heat transfer predictions in gas turbines. In: Proceedings of the International Gas Turbine Congress, 2-7 November 2003, Tokyo, Japan

35. Anderson JD (2010) Fundamentals of aerodynamics, 5th edn. McGraw-Hill Education, New York

36. Winslow J, Otsuka H, Govindarajan B, Chopra I (2018) Basic understanding of airfoil characteristics at low Reynolds numbers (104-105). J Aircr 55:1050-1061. https://doi.org/10.2514/1. C034415

37. Shah NA, Animasaun IL, Ibraheem RO, Babatunde HA, Sandeep N, Pop I (2018) Scrutinization of the effects of Grashof number on the flow of different fluids driven by convection over various surfaces. J Mol Liq 249:980-990. https://doi.org/10.1016/j.molli q.2017.11.042

38. Animasaun IL, Ibraheem RO, Mahanthesh B, Babatunde HA (2019) A meta-analysis on the effects of haphazard motion of tiny/nano-sized particles on the dynamics and other physical properties of some fluids. Chin J Phys 60:676-687. https://doi. org/10.1016/j.cjph.2019.06.007

Publisher's Note Springer Nature remains neutral with regard to jurisdictional claims in published maps and institutional affiliations. 